\title{
通过 “点击化学”对石墨烯和氧化石墨烯进行功能化改性
}

\author{
来常伟孙莹杨洪张雪勤林保平* \\ (东南大学化学化工学院 南京 211189)
}

\begin{abstract}
摘要 点击化学具有操作简单方便、灵活高效等特点, 在石墨烯的功能化改性上具有极其重要的应用. 本工作针对点 击化学对石墨烯和氧化石墨烯功能化改性方面进行了综述. 将石墨烯点击功能化改性方法分为两种情况: 共价键结合 的点击功能化改性和非共价键作用的点击功能化改性, 其中共价键结合又可细分为边缘点击功能化改性和表面点击功 能化改性. 首先, 本工作对石墨烯点击功能化改性的反应过程和反应条件及其研究方法作了详细的归类和系统的总结. 一方面，在石墨烯点击功能化改性的分类上包括：氧化石墨烯边缘点击，氧化石墨烯表面点击，石墨烯表面点击，石墨 烯表面经过 Diels-Alder [4+2]的点击反应，以及通过非共价键作用的 $\pi-\pi$ 堆积之后的点击反应；另一方面，在点击反应 的合成路线上，详细列出了对石墨烯或者氧化石墨烯进行炔基化或者叠氮基化以及功能化分子进行相应地叠氮基化或 者炔基化的连接方法和反应条件，通过点击反应将两部分连接起来，并指出石墨烯功能化复合物的功能特性和应用前 景. 对这部分工作进行列表总结, 然后作图列出石墨烯和氧化石墨烯的点击功能化反应的具体分类和反应过程. 另外, 本工作列表总结了 IR, Raman, UV, ${ }^{1} \mathrm{H}$ NMR, ${ }^{13} \mathrm{C}$ NMR, XPS, XRD, AFM, TEM, SEM, CV, TGA 等对石墨烯和氧化石墨 烯进行表征的常用方法, 指出了常见的出峰位置以及表征结果和测试目的, 并作了简要的分析和说明. 最后, 对点击 化学在石墨烯和氧化石墨烯上的功能化应用作出了总结和展望.
\end{abstract}

关键词 点击化学; 石墨烯; 氧化石墨烯; 功能化

\section{The Functionalization of Graphene and Graphene Oxide via Click Chemistry}

\author{
Lai, Changwei Sun, Ying Yang, Hong Zhang, Xueqin Lin, Baoping* \\ (College of Chemistry and Chemical Engineering, Southeast University, Nanjing 211189)
}

\begin{abstract}
Click chemistry has been widely applied to the functionalization of graphene due to its special properties of easy process, flexibility and high efficiency. In this paper, we have present a detailed review of the functionalization of graphene and graphene oxide via click chemistry. The functionalization methods through click chemistry can be divided into two main strategies of the covalent functionalization and the non-covalent functionalization. In addition, the former is further discussed in term of chemical bonds formed on the edge of graphene and chemical bonds formed on the surface of graphene via click chemistry. First, we provide a detailed classification and summary of the reaction process, condition and characterization of the functionalization through click chemistry. On the one hand, according to the position where the click chemistry takes place, the clicking functionalization of graphene can be classified into click reaction on the edge of the graphene oxide, click reaction on the surface of the graphene oxide, click reaction on the surface of the graphene, Diels-Alder [4+2] click reaction on the surface of the graphene, and click chemistry via $\pi-\pi$ non-covalent functionalization. Moreover, we have presented and discussed significant research references related to the above five parts. On the other hand, the synthetic routes including the linking methods, click reaction conditions, reaction conditions of the alkynylation and azido functionalization of the graphene, graphene oxide, and the corresponding reactants have been summarized and listed. In addition, the functional properties and the potential applications of the functionalized graphene and graphene oxide are also concluded. To further clearly illustrate and make a summary of the functionalization method of graphene and graphene oxide via click chemistry in details, a table is listed and shown in the paper. Furthermore, we have elaborate the common characterizations methods including IR, Raman, UV, ${ }^{1} \mathrm{H}$ NMR, ${ }^{13} \mathrm{C}$ NMR, XPS, XRD, AFM, TEM, SEM, CV, TGA, and the common characterization results are analyzed and briefly discussed. At last, the potential application of click chemistry on the functionalization of graphene and graphene oxide was summarized.
\end{abstract}

Keywords click chemistry; graphene; graphene oxide; functionalization

* E-mail: 1bp@seu.edu.cn; Tel.: 025-52090616

Received March 14, 2013; published May 24, 2013.

Project supported by the National Natural Science Foundation of China (No. 21002012) and the Jiangsu Provincial Natural Science Foundation (Nos. BK2011588, BY2011153).

项目受国家自然科学基金(No. 21002012)和江苏省自然科学基金(Nos. BK2011588, BY2011153)资助. 


\section{1 引言}

2004 年, 英国曼彻斯特大学的两位俄裔科学家 Geim 和 Novoselov ${ }^{[1]}$ 通过胶带剥离的方法制得石墨烯, 石墨烯中每个 $\mathrm{C}$ 原子以 $\mathrm{sp}^{2}$ 杂化, 形成独特的二维六角 蜂窝状的晶格结构, 可以看做单原子层的石墨 ${ }^{[2]}$. 石墨 烯具有优异的力学性能 ${ }^{[3]}$ 、热学性能 ${ }^{[4]}$ 和电学性能 ${ }^{[5]}$ 二 极场效应 ${ }^{[6]}$ 、大比表面积 ${ }^{[7]}$ 和高透明度 ${ }^{[8,9]}$ 等特殊的物理

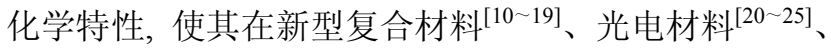

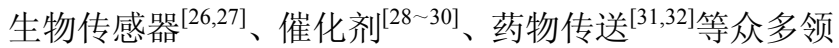
域中有着广泛的应用.

石墨烯常见的制备方法有微机械剥离法 ${ }^{[1]}$ 、化学气 相沉积法 ${ }^{[33,34]}$ (CVD)、外延生长法 ${ }^{[35]}$ 、液相去角质法 ${ }^{[36]}$ 和氧化还原法 ${ }^{[37 ~ 41]}$ 等, 其中氧化还原法是应用最为广 泛的可行性技术, 不仅可以实现量化生产, 而且还可以 提供具有良好可加工性和功能化的石墨烯。通过 Hummers 法 $^{[42]}$ 将石墨氧化成为氧化石墨, 在超声条件 下分散可得到单层的氧化石墨烯的分散溶液, 再通过化 学还原获得石墨烯. 氧化石墨烯具有和石墨烯相类似的 平面结构, 在氧化石墨烯的面上与边缘上含有大量的基 团 ${ }^{[43 \sim 47]}$, 如羟基、环氧基、羰基、羧基、酯基等.

由于石墨烯本身的不溶性以及片层之间存在范德 华力和 $\pi-\pi$ 堆积作用. 通常情况下, 石墨烯在水和有机 介质中容易发生不可逆的聚集和沉淀, 这就极大地限制 了石墨烯的应用. 因此, 石墨烯的功能化应用就显得至 关重要. 石墨烯的功能化可分为共价键结合和非共价键 作用两种方式, 其中, 共价键结合需要通过一定的化学 反应使功能化分子与石墨烯连接起来, 与非共价键作用 相比共价键连接具有相对较高的稳定性, 并且改性后复 合材料具其它方面的优异性，但其反应操作难度较大， 而且反应条件也较为苛刻; 而非共价键作用则靠的是石 墨烯和含有芳香基团的功能化改性分子之间的 $\pi-\pi$ 堆积 作用以及范德华力结合在一起的, 对石墨烯的共轭结 构、机械性能以及电化学性能影响较小, 而且反应操作 也较为简单方便, 属于环境友好型的化学反应, 但是与 共价键结合相比则稳定性较差. 在诸多的石墨烯的功能 化改性方法中 ${ }^{[48 ~ 65]}$, 点击化学起着重要的作用. 在点击 反应中, 氮三唑具有芳香性, 如果所连接的两个部分都 具有共轭结构, 那么氮三唑可以扩展分子的共轭区域, 使得电子有了更大范围的传输, 如果不考虑共轭性, 氮 三唑也可以起到最基本的桥连作用 ${ }^{[66]}$. 而且, 通过点击 化学反应已经成功的将大分子连接在了碳纳米管 ${ }^{[67]}$ 和 富勒烯 ${ }^{[68]}$ 上, 同样也为石墨烯的功能化改性提供新的 研究平台和实验方法.

“点击化学” ${ }^{[69]}$ (Click Chemisry) 是美国化学家 Sharpless 提出的一种化学合成的新方法, 是继组合化学 之后又一给传统有机合成化学带来重大革新的合成技 术. 目前 ${ }^{[70]}$, 在众多研究领域得到迅速发展 ${ }^{[71]}$, 并在有

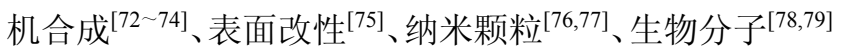

等方面有着广泛的应用，例如 $\mathrm{DNA}^{[80] \text { 、自组装 }}{ }^{[81]}$ 、表 面修饰 ${ }^{[82]}$ 、超分子化学 ${ }^{[83]}$ 、树枝状分子 ${ }^{[84]}$ 、功能聚合

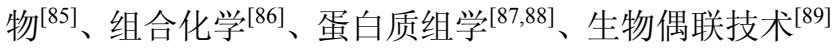
和生物医药 ${ }^{[90]}$ 等.

在点击反应中, 铜催化的端基炔与叠氮化合物之间 的 Huisgen ${ }^{[91]} 1,3$-偶极环加成反应是最常用的, 具有如 下特征 ${ }^{[92]}$ : (1)反应原料易得; (2)反应操作简单，条件温 和，对氧和水不敏感，反应非常可靠; (3)产物立体选择 性好，收率高; (4)产物易分离，后处理简单.

在石墨烯的众多功能化改性方面上, 由于点击化学 有独特的优良效果，因此将这两个科研领域的研究热点 联系在一起, 通过点击化学反应对石墨烯进行功能化改 性，使得石墨烯有了更加广泛的应用. 本文根据点击化 学在石墨烯和氧化石墨烯功能化改性方面的合成和应 用等相关文献做简要总结, 并将石墨烯和氧化石墨烯的 点击功能化改性分为两种情况: 即共价键结合的点击功 能化改性和非共价键作用的点击功能化改性, 其中共价 键结合又可细分为边缘点击功能化改性和表面点击功 能化改性. 然后, 对石墨烯和氧化石墨烯的点击功能化 改性的反应过程和反应条件及其研究方法作了详细的 归类和系统的总结，通过列表和作图来介绍石墨烯点击 功能化反应的具体分类和反应过程，并对一些常用的表 征方法及性质检测作了简要的总结和说明.

\section{2 共价键结合的石墨烯点击功能化改性}

石墨烯是二维平面结构, 氧化石墨烯具有相似的空 间二维结构，在二维平面的边缘和表面分布着不同类型 的官能团. 由于不同区域的官能团的反应活性差异较 大，因此功能化反应的类型也就相应不同. 基于共价键 功能化改性后, 功能化分子与石墨烯之间通过共价键相 连, 根据点击化学在石墨烯边缘或表面的功能化反应位 置不同将石墨烯的功能化改性分为两种情况: 一种是边 缘点击功能化改性, 另一种是表面点击功能化改性.

\section{1 边缘点击功能化改性}

通过 Hummers 氧化法, 可以制备大量氧化石墨烯. 在这些石墨烯的表面和边缘存在着大量的官能团, 其中 在表面上主要有环氧基和羟基，而在边缘上主要有羟 基、羧基、羰基、酯基(五元环、七元环)等缺陷结构存

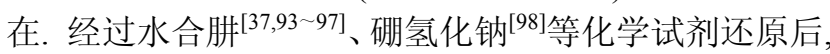
仍会有许多环氧基、羟基、䍭基、羰基存在. 尽管这些 缺陷影响了氧化石墨烯的共轭结构, 但却为它的功能化 提供了很好的反应活性点. 在氧化石墨烯边缘的羧基就 是功能化反应的活性点, 通过化学反应活化羧基或者通 过催化剂使功能化反应物与䍨基之间通过共价键连接 生成酯或酰胺, 从而对氧化石墨烯进行边缘点击功能化 改性.

2010 年, $\mathrm{Wu}$ 等 ${ }^{[99]}$ 第一次使用点击化学对氧化石墨 烯的边缘进行功能化改性, 并提高了氧化石墨烯在有机 
溶剂中的溶解分散性. 首先在 $70{ }^{\circ} \mathrm{C}$ 下, 使用 $\mathrm{SOCl}_{2}$ 与氧 化石墨烯(GO)回流 $24 \mathrm{~h}$, 来活化 $\mathrm{GO}$ 边缘上的羧基生成 酰氯, 然后再与炔丙醇在室温条件下经过 $24 \mathrm{~h}$ 酯化反 应, 得到炔基化的氧化石墨烯 $(\mathrm{GO}-\mathrm{C} \equiv \mathrm{CH})$, 再与叠氮 基聚苯乙烯通过点击化学反应, 将聚苯乙烯接枝在氧化 石墨烯上, 如图 1 所示. 此反应条件比较温和, 容易进 行而且产率较高. 经点击功能化改性后的氧化石墨烯在 常用的有机溶剂中有了良好的溶解分散性. 他们还提出 了, 通过聚苯乙烯改性后的石墨烯复合材料将在自组 装、药物传输和导电材料中有重要的潜在应用.

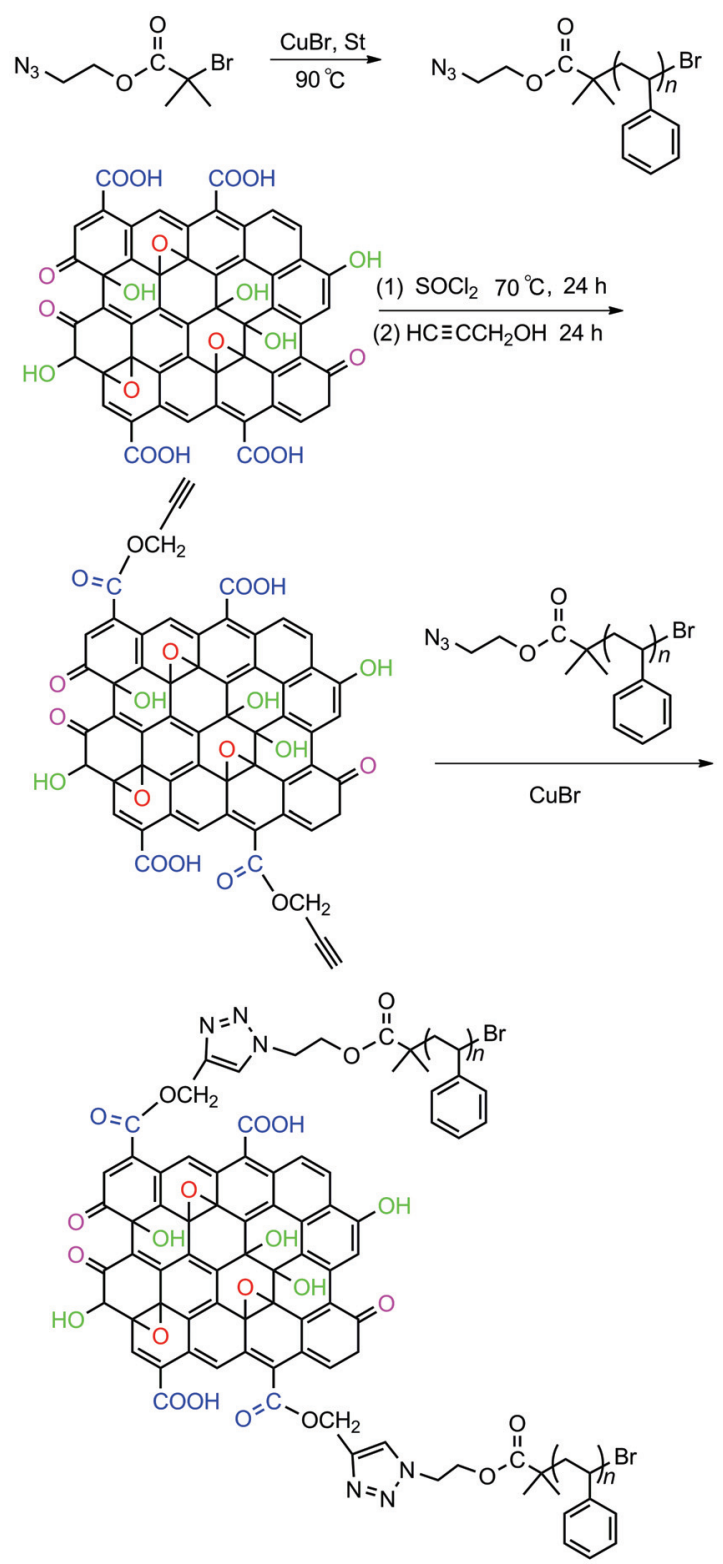

图 1 单分散的聚苯乙烯点击到氧化石墨烯上的合成路线

Figure 1 Synthesis route for "clicking" monodispersed PS onto GO sheets

$\mathrm{Wu}$ 等 ${ }^{[100]}$ 又在 2011 年报道了通过点击化学将氧化 石墨烯应用于材料的补强领域. 首先将氧化石墨烯片层 (GOS) 经 $\mathrm{SOCl}_{2}$ 活化后, 再与炔丙醇经过酯化反应, 得
到炔基化的氧化石墨烯 $(\mathrm{GO}-\mathrm{C} \equiv \mathrm{CH})$ ，然后和叠氮化的 聚(苯乙烯一乙烯一丁烯一苯乙烯)的三段共聚物(SEBS)通 过点击反应生成 SEBS 和 GOS 的功能化改性化合物 SEBS-c-GOS，如图 2 所示. 经 TGA 测试，其中 SEBS 在 复合物 SEBS-c-GOS 中的质量分数为 $35 \%$. 将含量为 $2.0 \%$ 的 SEBS-c-GOS 作为补强填料加入到聚苯乙烯(PS)
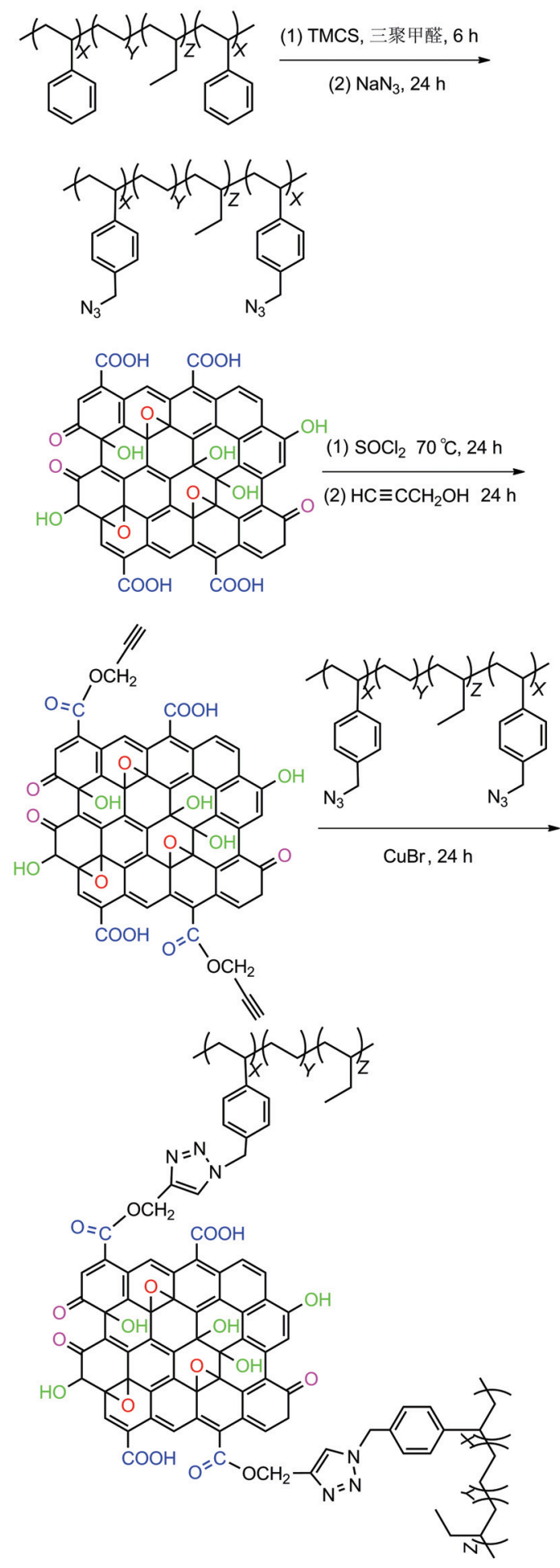

图 2 SEBS 点击到氧化石墨烯上的合成路线

Figure 2 Synthesis route for clicking SEBS onto GOS sheets 
中, 与单纯的 PS 相比较, 复合材料的拉伸强度增长 $78 \%$, 杨氏模量提高 $73 \%$, 而且 SEBS-c-GOS 在 PS 中具 有良好的界面连接性, 展现出良好的相容性, 显著提高 了复合膜的机械性能和热稳定性. 他们还指出, 通过点 击反应不仅扩大了 GOS 的应用范围, 而且在材料补强 应用领域有重要的意义.

$\mathrm{Kim}$ 等 ${ }^{[101]}$ 使用点击化学将作为催化剂载体的 GO 与 $\mathrm{CuPt}$ 纳米粒子连接起来, 并应用于催化剂领域. 首 先, 使用 $\mathrm{SOCl}_{2}$ 活化 $\mathrm{GO}$, 再与炔丙醇经过酯化反应, 得 到炔基化的氧化石墨烯 $(\mathrm{GO}-\mathrm{C} \equiv \mathrm{CH})$, 然后与通过配位 交换法 ${ }^{[102]}$ 制得叠氮化的 $\mathrm{CuPt}$ 纳米粒子 $\mathrm{CuPt}-\mathrm{N}_{3}$ (有多种 形状, 长宽比分别为 $\mathrm{AR}=1,5,11)$ 进行化学点击反应, 得到 $\mathrm{CuPt}$ 粒子分散在 $\mathrm{GO}$ 周边的功能化改性的纳米复 合物 CuPt-GO, 如图 3 所示. CuPt-GO 是以 GO 作为催化 剂载体通过共价键连接, 在水相中可以模仿酶的反应类 型, 将邻苯二胺(ODP)氧化成 2,3-二氨基吩嗪, 并显示 良好的催化活性. 通过使用含 Pt 量相同的多个类型的 CuPt 催化剂样品对 ODP 进行催化氧化, 并使用 UV-vis 光谱在 $425 \mathrm{~nm}$ 处测试氧化反应的进度, 以确定各个催 化剂样品的催化活性. 结果显示, $\mathrm{GO}$ 和 $\mathrm{CuPt}-\mathrm{N}_{3}$ 均不显 示催化性能, 而 CuPt-GO 的催化活性明显增加, 其中 CuPt-GO $(\mathrm{AR}=1)$ 的催化活性明显高于其他棒状的 CuPt-GO $(\mathrm{AR}=5,11)$, 这是由于不同形状 $\mathrm{CuPt}$ 的纳米 粒子表面上 $\mathrm{Pt}$ 的含量不同. 他们还指出, 这种方法可以 扩展到其它功能性纳米粒子与石墨烯之间的复合连接 设计, 可以应用于电子和环境等相关研究领域.

Salavagione 等 ${ }^{[103]}$ 报道了叠氮基的共轭高聚物 9,9二己基苆和 9,9-双-(6-叠氮基已基芴)交替共聚物 (PFA- $N_{3}$ ) 通过点击化学分别在 $\mathrm{GO}$ 的边缘和 $\mathrm{G}$ 的表面进 行功能化改性, 分别得到了产物 PFA-GO 与 PFA-G. 其 中 $\mathrm{GO}$ 的边缘点击功能化改性的步骤具体如下: 首先使 用 $\mathrm{SOCl}_{2}$ 来活化 $\mathrm{GO}$ 边缘上的羒基生成酰氯, 然后在室 温下与炔丙胺摚拌过夜进行酰胺化反应, 得到炔基化的 氧化石墨烯 $(\mathrm{GO}-\mathrm{C} \equiv \mathrm{CH})$, 再与 $\mathrm{PFA}-\mathrm{N}_{3}$ 通过点击化学反 应, 得到化合物 PFA-GO, 如图 4 所示. 另外, 关于对 G 的表面点击功能化改性以及化合物 PFA-G 的应用说明, 详见 2.2.2 节部分.

2010 年, Gao 等 ${ }^{[104]}$ 在氧化石墨烯的边缘点击功能 化改性中, 首次报道了通过酰胺化的方法制备了叠氮基 化的氧化石墨烯. 首先在 1-(3-二甲氨基丙基)-3-乙基 碳二亚胺(EDC)和 $N$-差基琥珀酰亚胺(NHS)的催化作用 下, 将 $\mathrm{GO}$ 与 3-叠氮基丙胺 $\left(\mathrm{NH}_{2} \mathrm{CH}_{2} \mathrm{CH}_{2} \mathrm{CH}_{2} \mathrm{~N}_{3}\right.$ ) 在室温 下反应 $24 \mathrm{~h}$, 生成叠氮基氧化石墨烯 $\left(\mathrm{GO}-\mathrm{N}_{3}\right)$. 然后再 分别与炔基聚乙二醇 $(\mathrm{PEG}-\mathrm{C} \equiv \mathrm{CH}$ ), 炔基聚苯乙烯 $(\mathrm{PS}-\mathrm{C} \equiv \mathrm{CH})$ ，炔基甘氨酸 $(\mathrm{Gly}-\mathrm{C} \equiv \mathrm{CH}$ ), 炔基苯丙氨酸 $(\mathrm{Phe}-\mathrm{C} \equiv \mathrm{CH}$ ) 以及棕榈酸炔丙酯等, 通过点击反应对 $\mathrm{GO}$ 进行功能化改性, 如图 5 所示. 在 $\mathrm{GO}$ 的平面上得到 $2 \mathrm{D}$ 分子刷和氨基酸固定化的纳米片层. 经过改性后的

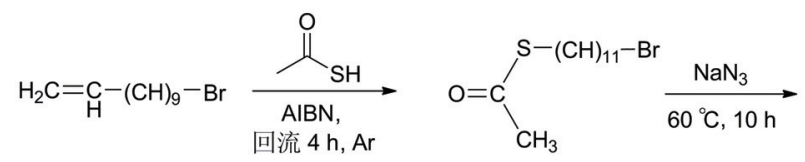

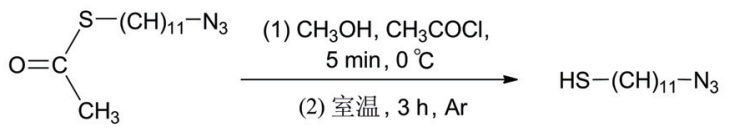

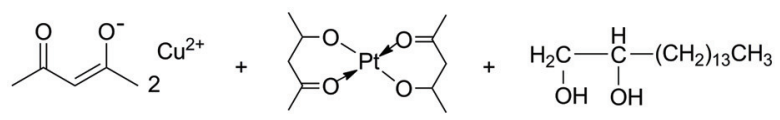

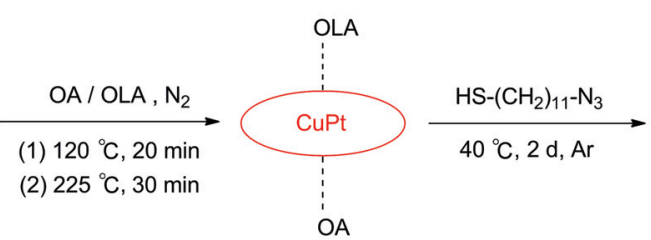

$\mathrm{N}_{3}-\left(\mathrm{CH}_{2}\right)_{11}-\mathrm{SH} \quad \mathrm{HS}-\left(\mathrm{CH}_{2}\right)_{1}-\mathrm{N}_{3}$

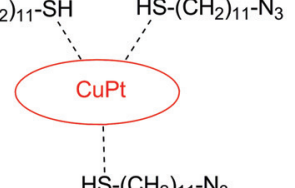

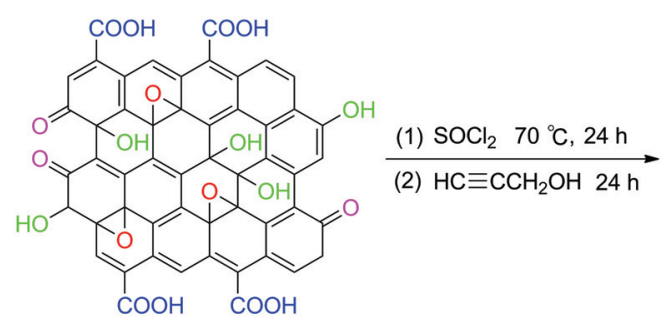<smiles>C#COCC</smiles>

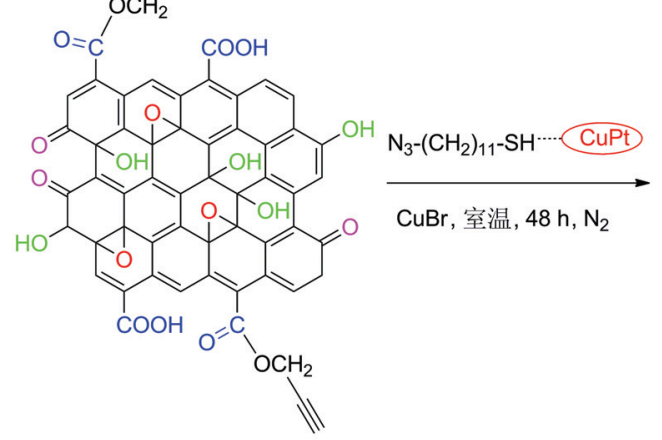

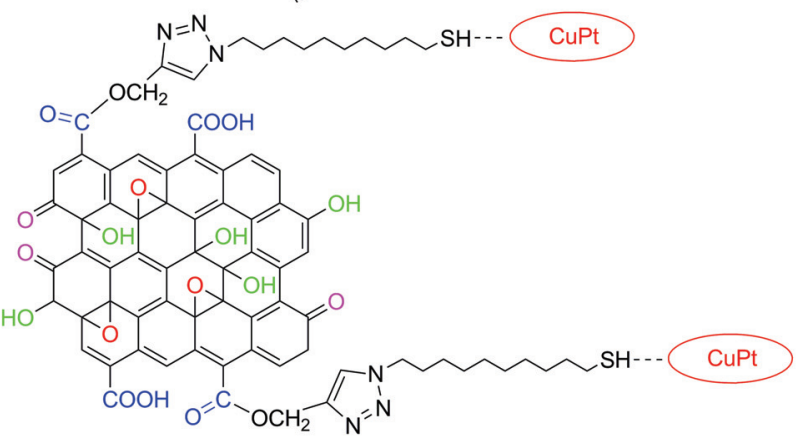

图 $3 \mathrm{HS}-\left(\mathrm{CH}_{2}\right)_{11}-\mathrm{N}_{3}{ }^{[102]}, \mathrm{CuPt}-\mathrm{N}_{3}$ 和 CuPt-GO 的路线 Figure 3 The synthesis route for HS- $\left(\mathrm{CH}_{2}\right)_{11}-\mathrm{N}_{3}{ }^{[102]}, \mathrm{CuPt}-\mathrm{N}_{3}$ and CuPt-GO 
氧化石墨烯在三氯甲烷、二氯甲烷等有机溶剂中有较好 的溶解性, 将在大分子或生物分子功能化修饰石墨烯方 面有重要的应用。
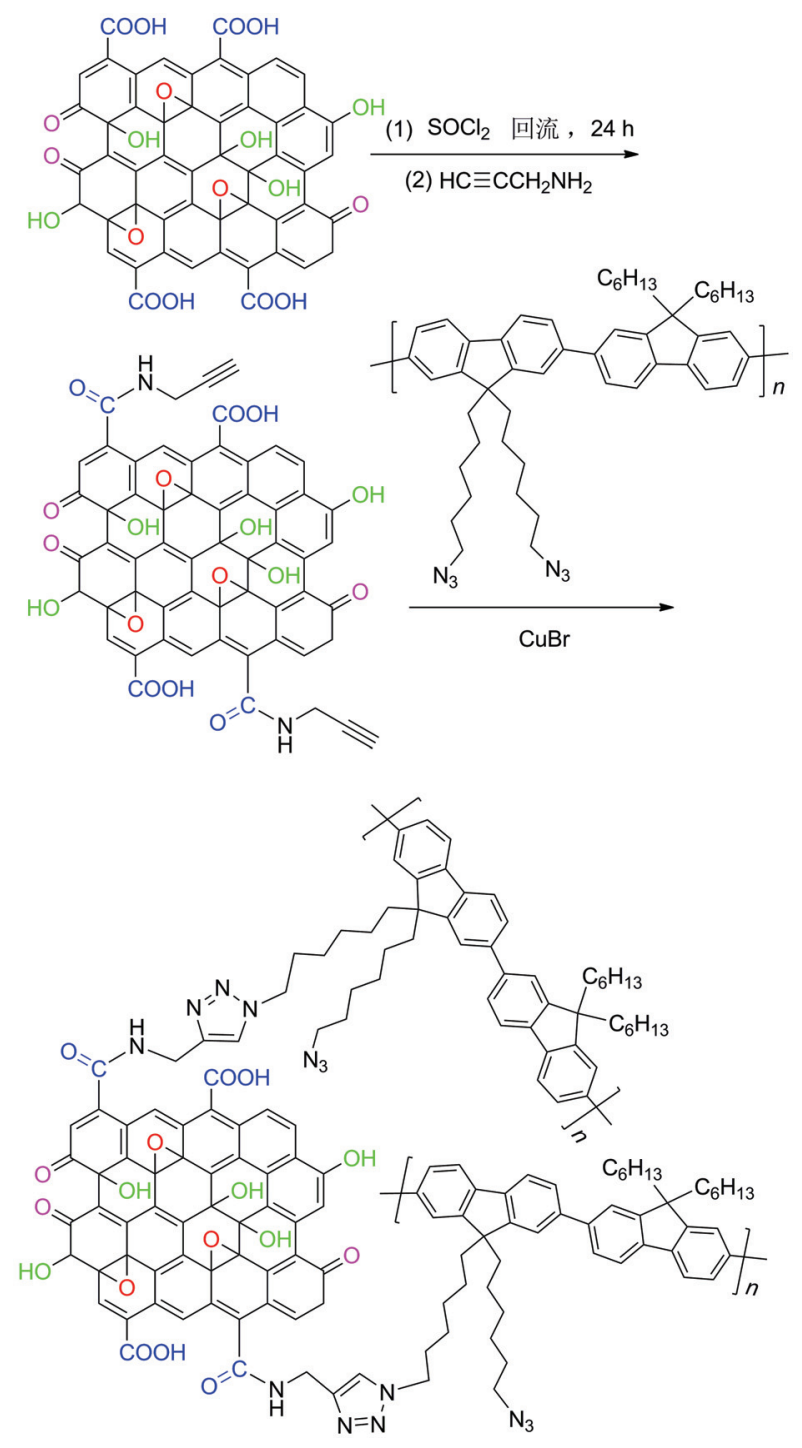

图 4 氧化石墨烯边缘点击功能化合成 PFA-GO 的路线

Figure 4 The synthesis route for PFA-GO at the edge of GO with Click Chemistry

$\mathrm{Li}$ 等 ${ }^{[105]}$ 通过点击化学将聚 $(N$-异丙基丙烯酰胺)接 枝到氧化石墨烯上，作为药物载体应用于药物传输领 域. 首先在 $N, N^{\prime}$-二环己基碳二亚胺(DCC)和 4-二甲 氨基吡啶 (DMAP) 的催化作用下, 将 $\mathrm{GO}$ 与炔丙胺 $\left(\mathrm{NH}_{2} \mathrm{CH}_{2} \mathrm{C} \equiv \mathrm{CH}\right)$ 在室温下搅拌 $16 \mathrm{~h}$, 反应生成炔基化 的氧化石墨烯 $(\mathrm{GO}-\mathrm{C} \equiv \mathrm{CH})$ ，然后再与端基为叠氮基的 聚 $(N$-异丙基丙烯酰胺)(PNIPAM)通过点击化学在氧化 石墨烯上接枝一个具有良好热响应的 PNIPAM, 制备得 到了功能化改性的复合物 PNIPAM-GOS, 如图 6 所示. 其中 PNIPAM 聚合物约占 $50 \%$, 在生理盐溶液中具有良 好的溶解性和稳定性. 此外, 芳香药物和 PNIPAM-GOS 复合物之间通过 $\pi-\pi$ 堆积作用和疏水作用，使得
PNIPAM-GOS 上可以加载不溶于水的抗癌药物喜树碱 $(\mathrm{CPT})$, 加载量为 $15.6 \%$ (即 $0.185 \mathrm{~g} \mathrm{CPT}$ 加载于 $1 \mathrm{~g}$ PNIPAM-GOS). 他们还分别在人体外温度为 $37{ }^{\circ} \mathrm{C}$ 的水 和磷酸盐缓冲液中, 对 PNIPAM-GOS-CPT 复合物进行 药物释放实验。更重要的是, 在体外 PNIPAMGOS-CPT 显示了高效的杀死癌细胞的能力, 并且没有 毒性. 因此, PNIPAM-GOS 是一个很好的抗癌药物输送 载体.
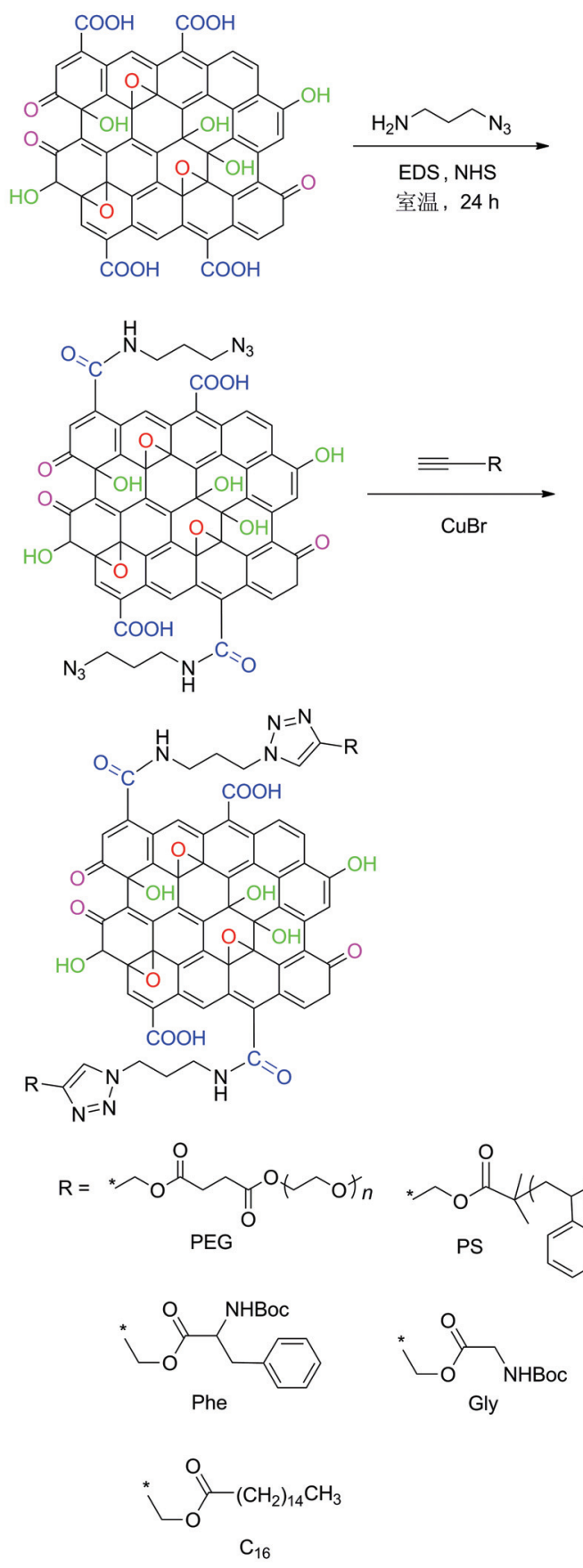

图 5 通过点击化学的功能化反应制备 $\mathrm{GO}$ 的二维高分子纳米复合物 Figure 5 Functionalization of 2D macromolecular of GO nanosheets by azide-alkyne Click Chemistry 
<smiles>CCOC(=O)C(C)C(Cl)(Cl)Cl</smiles><smiles>CC(C)NC(=O)C(C)CC(C)C(=O)OCCC#N</smiles>

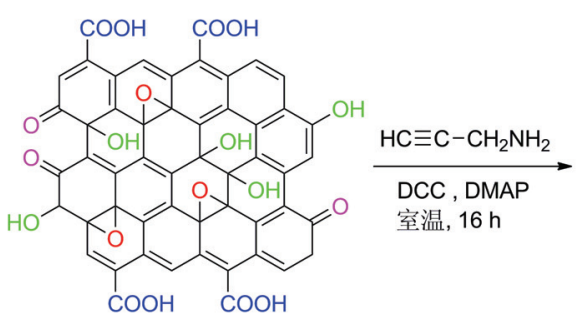

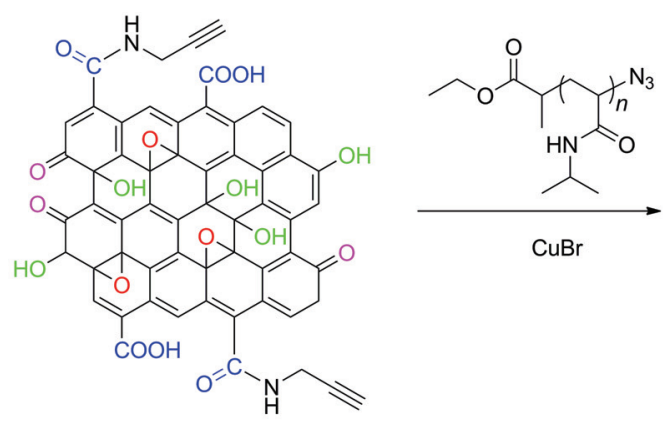

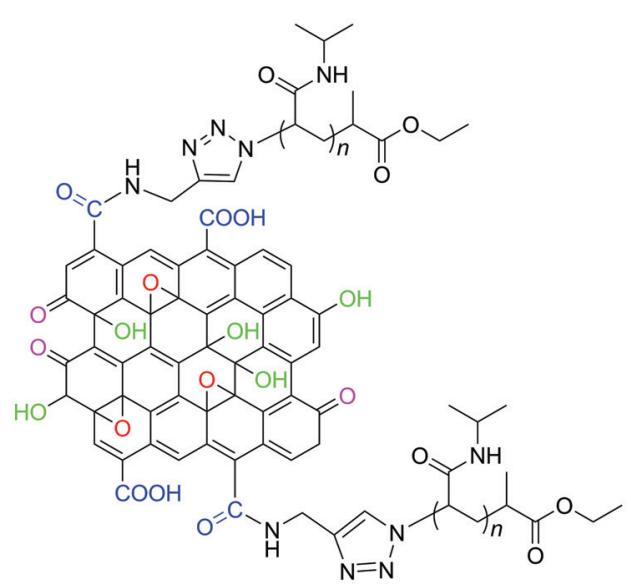

图 6 PNIPAM-GOS 的合成路线

Figure 6 Synthesis route of PNIPAM-GOS

由上述文献总结可知, 由于氧化石墨烯的边缘存在 大量的羧基官能团, 这是功能化改性的反应活性点, 因 此边缘点击功能化改性的具体步骤可分为: (1)首先用亚 硫酰氯或碳化二亚胺作为羧基活化剂, 将氧化石墨烯边 缘的羧基活化. (2)通过酯化或者酰胺化反应, 生成炔基 化或叠氮基化的氧化石墨烯衍生物. (3)再分别与端基为 叠氮基或炔基的功能化分子通过化学点击反应, 对氧化 石墨烯进行边缘点击功能化改性.

\section{2 表面点击功能化改性}

由于石墨烯和氧化石墨烯的表面点击功能化改性 的具体反应类型不同, 因此功能化改性的情况比较复 杂，反应方式和反应条件差别也比较大. 在氧化石墨烯 的表面上有大量的环氧基(C-O-C)和羟基 $(\mathrm{C}-\mathrm{OH})$, 这些 官能团就是功能化反应的活性点, 通过这些活性点对氧 化石墨烯的表面进行点击功能化改性. 而在石墨烯面上 的 $\mathrm{C}$ 原子为 $\mathrm{sp}^{2}$ 杂化, 含有大量的 $\mathrm{C}=\mathrm{C}$ 双键. 因此, 含 有炔基的芳香胺类化合物的重氮盐离子(或者重氮化合 物)经过脱氮气之后，能够形成芳香基自由基，然后对 石墨烯进行加成反应，与石墨烯之间通过 $\mathrm{C}-\mathrm{C}$ 单键连 接起来，分布在石墨烯的表面. 另外，石墨烯表面上的 $\mathrm{C}=\mathrm{C}$ 双键, 可以作为亲双烯体, 在加热的条件下可与 双烯体进行 D-A [4+2]环加成的点击反应，通过 D-A [4 $+2]$ 反应对石墨烯的表面进行点击功能化改性.

\subsection{1 氧化石, 墨烯的表面点击功能化改性}

在氧化石墨烯表面上的环氧基(C-O-C)和羟基 $(\mathrm{C}-\mathrm{OH})$ 是功能化反应的活性点. 通过对环氧基开环加 成、羟基酯化等反应对氧化石墨烯进行共价键连接，经 叠氮基取代后得到叠氮化的氧化石墨烯 $\left(\mathrm{GO}-\mathrm{N}_{3}\right)$, 然后 与带有炔基功能化分子通过点击化学反应对氧化石墨 烯的表面进行点击功能化改性.

2009 年, Wiel 等 ${ }^{[106]}$ 首次报道了通过点击化学对氧 化石墨烯进行功能化改性. 首先将 GO 分散在水和乙腈 比例为 $1: 1$ 的混合液中, 在 $\mathrm{N}_{2}$ 保护下与 $\mathrm{NaN}_{3}$ 加热回 流 $7 \mathrm{~d}$, 得到 $\mathrm{GO}$ 的叠氮衍生物 $\left(\mathrm{GO}-\mathrm{N}_{3}\right)$, 然后与十八烷 炔 $\left(\mathrm{CH} \equiv \mathrm{CC}_{16} \mathrm{H}_{33}\right)$ 在室温下摚拌 $10 \mathrm{~d}$, 通过点击化学反 应得到 GO 的功能化改性化合物(GO-C 18 ), 如图 7 所示. 通过点击化学将长烷基链连接到 $\mathrm{GO}$ 上, 可用来制备可 溶性的单层氧化石墨烯材料.

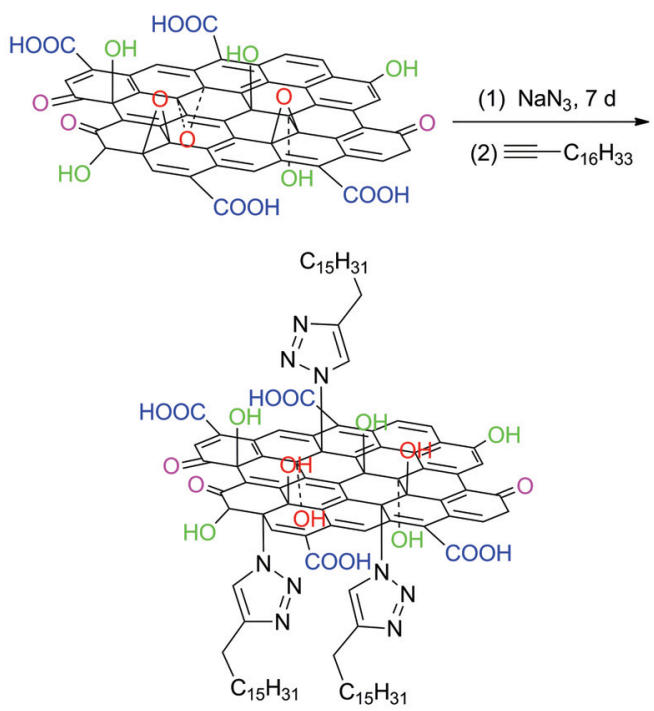

图 7 GO- $\mathrm{C}_{18}$ 的合成方法

Figure 7 The synthesis of the $\mathrm{GO}^{-\mathrm{C}_{18}}$ 
$\mathrm{Tu}$ 等 ${ }^{[107]} 2011$ 年首次报道了将氧化石墨烯表面的羟 基经酯化和取代反应后，制备了表面叠氮基化的氧化石 墨烯，扩展了氧化石墨烯表面点击功能化改性的方法. 首先将 $\mathrm{GO}$ 和 2 -溴异丁酰澳常温下傥拌 $2 \mathrm{~d}$, 经酯化反应 后分散在 DMF 中, 再加入 $\mathrm{NaN}_{3}$ 室温下搅拌 $24 \mathrm{~h}$, 反应 制得叠氮基改性的氧化石墨烯 $\left(\mathrm{GO}-\mathrm{N}_{3}\right)$. 用 Grayson's 法 ${ }^{[108]}$ 制备的含炔基的聚苯乙烯 $(\mathrm{HC} \equiv \mathrm{C}-\mathrm{PS})$, 通过点击 反应将聚苯乙烯接枝到 $\mathrm{GO}$ 表面上, 得到复合物 GO-PS, 如图 8 所示. 经点击功能化改性后的 GO 在 THF, DMF 和 $\mathrm{CHCl}_{3}$ 等有机溶剂中有较好的溶解性. 他们还观测到 GO-PS 之间的有序结构层，而且 GO 层之间的距离可以 通过 PS 的长度来控制. 当所接枝的 PS 的分子量 $M_{\mathrm{n}}$ 分 别为 $2.9 \mathrm{~kg} / \mathrm{mol}$ 和 $6.4 \mathrm{~kg} / \mathrm{mol}$ 时, 经 XRD 测试, 改性后 的 GO 与改性前的 GO 层之间的距离相比分别增加了 $0.19 \mathrm{~nm}$ 和 $0.40 \mathrm{~nm}$, 见表 1 . 他们还正在将此方法扩展 到其它功能高分子和材料在 $\mathrm{GO}$ 上的功能化.
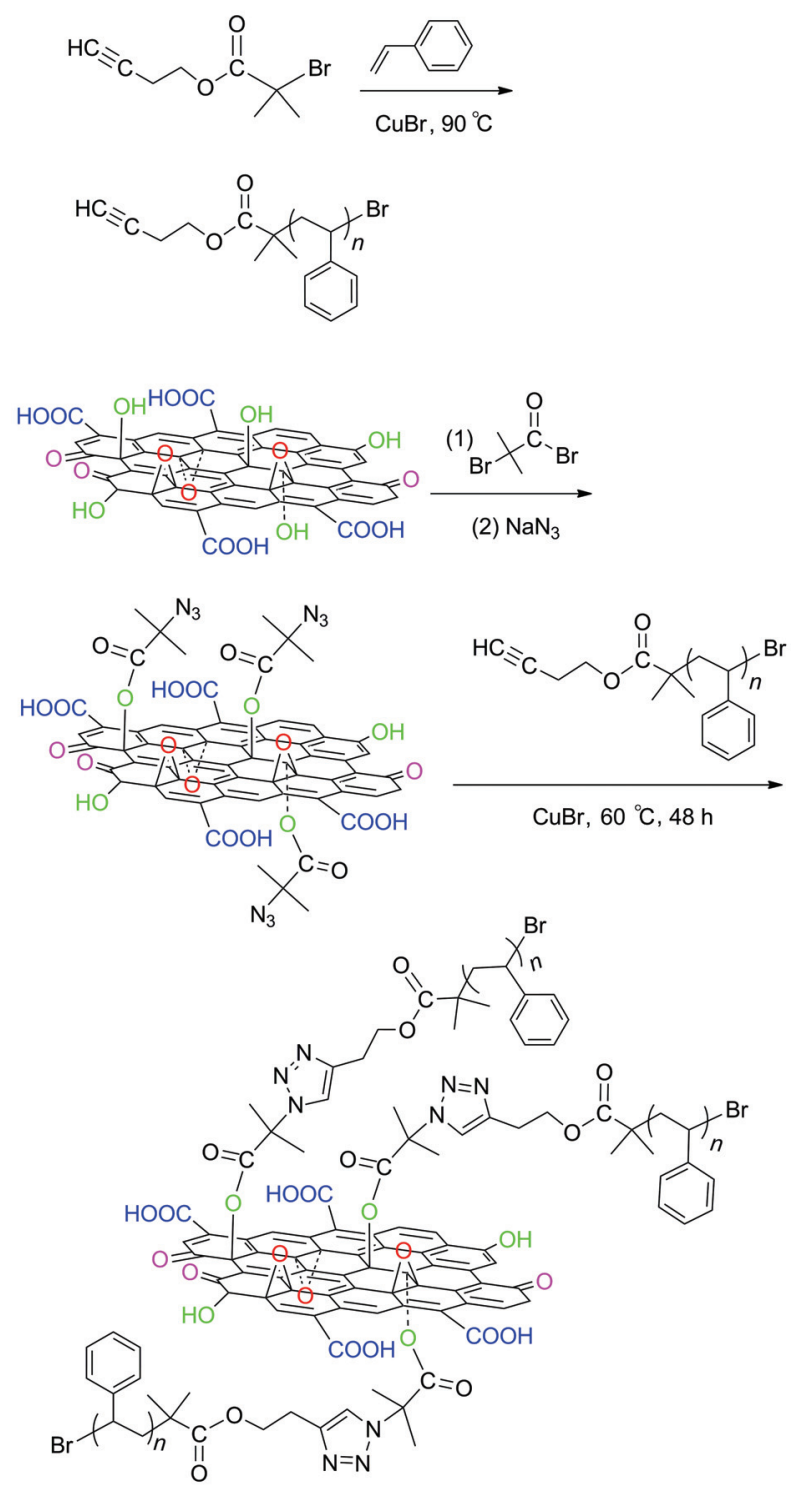

图 8 聚苯乙烯接枝氧化石墨的合成路线

Figure 8 Synthesis route of polystyrene graft GO (GO/PS)
表 1 样品 $\mathrm{G}, \mathrm{GO}, \mathrm{GO} / \mathrm{PS} 2.9 \mathrm{~K}$ 和 GO/PS6.4K 的 XRD 结果中 $2 \theta$ 和层 间距

Table 1 The $2 \theta$ and distance between layers of the samples G, GO, $\mathrm{GO} / \mathrm{PS} 2.9 \mathrm{~K}$ and GO/PS6.4K

\begin{tabular}{ccc}
\hline 样品名称 & $2 \theta /\left(^{\circ}\right)$ & 层间距离 $/ \mathrm{nm}$ \\
\hline $\mathrm{G}$ & 26.40 & 0.337 \\
$\mathrm{GO}$ & 9.68 & 0.968 \\
$\mathrm{GO} / \mathrm{PS} 2.9 \mathrm{~K}$ & 7.61 & 1.16 \\
$\mathrm{GO} / \mathrm{PS} 6.4 \mathrm{~K}$ & 6.43 & 1.37 \\
\hline
\end{tabular}

由表 1 的 XRD 结果分析可知, 样品 $\mathrm{G}, \mathrm{GO}$, $\mathrm{GO} / \mathrm{PS} 2.9 \mathrm{~K}$ 和 $\mathrm{GO} / \mathrm{PS} 6.4 \mathrm{~K}$ 的 $2 \theta$ 角逐渐减小, 说明相应 的层间距离也在逐渐增大.

为了扩展氧化石墨烯在生物检测方面的应用, Huang 等 ${ }^{[109]}$ 利用点击化学制备了氧化石墨烯与 DNA 之 间通过共价键连接的复合物，并进一步制备了性能优良 的检测器件. 首先将 $\mathrm{GO}$ 与 2 -氯乙基异氰酸酯在 $\mathrm{N}_{2}$ 保护 下摚拌 $24 \mathrm{~h}$, 产物经处理后, 溶解到二甲基亚砜中, 再 加入 $\mathrm{NaN}_{3}$ 在 $50{ }^{\circ} \mathrm{C}$ 下搅拌并回流 $48 \mathrm{~h}$, 得到叠氮基石墨 烯衍生物 $\left(\mathrm{GO}-\mathrm{N}_{3}\right)$. 然后与炔基功能化的 DNA 通过点击 反应制得共价键结合的 DNA-G, 如图 9 所示. 他们用柠 檬酸三钠加入沸腾的 $\mathrm{HAuCl}_{4}$ 溶液中, 并保持快速摚拌
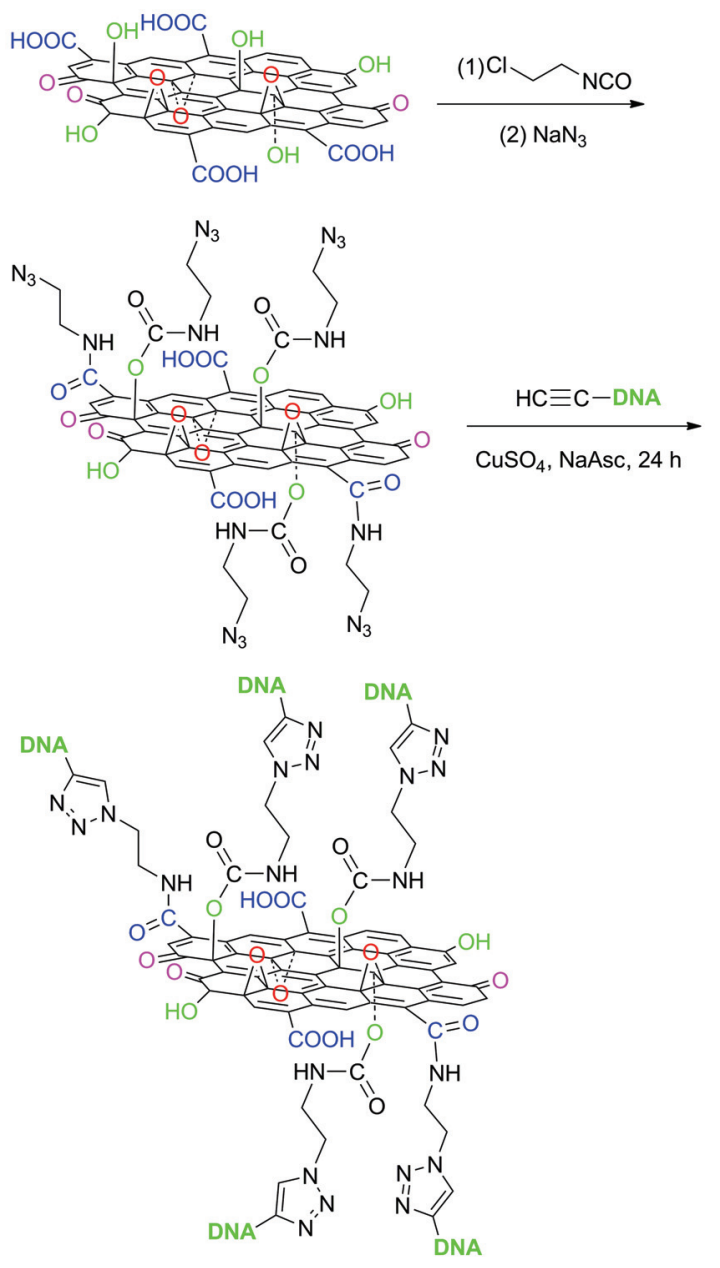

图 9 DNA-G 复合物的合成路线

Figure 9 Synthesis route of DNA-Graphene conjugates 
$20 \mathrm{~min}$, 冷却至室温处理后再加入統基化的 DNA, 室温 孵育 $16 \mathrm{~h}$, 制得 DNA-Au 纳米粒子(DNA-AuNPs), 再与 DNA-G 混合处理后, 离心分离可得 DNA-AuNPs 和 DNA-G 结合的组件(Au-DNA-G). 该组件显示出优良的 稳定性, 具有良好的耐表面活性剂破坏的性能. 经过与 DNA 组装后制得四面体探头(TSPs), 该纳米复合物显 示出优异的电致发光性, 这可能用来制造 DNA 生物检 测传感器.

由上述文献总结可知, 氧化石墨烯作为反应底物, 与其他活性反应物进行表面点击功能化反应，具体步骤 可分为：(1)氧化石墨烯表面的环氧基或羟基(以及边缘 上的羧基)可与含有活性官能团的反应物发生反应，由 于反应类型不同, 所以反应情况比较复杂, 就目前所报 道的主要有这样 3 种情况: (1) $\mathrm{N}_{3}^{-}$对氧化石墨烯表面上 的环氧基加成开环反应; (2) 酰卤与氧化石墨烯表面上 的羟基进行酯化反应, 然后与叠氮钠进行取代反应; (3) 异氧酸酯可分别与氧化石墨烯表面上的羟基反应生成 酯以及边缘上羧基反应生成酰胺, 然后与叠氮钠进行取 代反应。通过这些反应, 得到叠氮化的氧化石墨烯 $\left(\mathrm{GO}-\mathrm{N}_{3}\right)$. (2)叠氮化的氧化石墨烯 $\left(\mathrm{GO}-\mathrm{N}_{3}\right)$ 再分别与端基 为炔基的功能化分子通过点击化学反应, 对氧化石墨烯 进行功能化改性.

\subsection{2 通过重氮盐(或重氮化合物)反应对石, 墨烯进行表} 面点击功能化改性

利用重氮盐反应, 在碳纳米管上的连接已经多有报

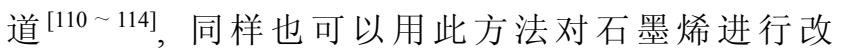
性 ${ }^{[115 ~ 120]}$. 当含有炔基的芳香胺类化合物形成重氮盐离 子或者重氮化合物, 经过得电子并脱氮气之后形成自由 基 ${ }^{[110,120,121]}$, 然后对石墨烯上的 $\mathrm{C}=\mathrm{C}$ 双键加成, 并生成 新的 $\mathrm{C}-\mathrm{C}$ 单键. 因此, 石墨烯与带有端炔基的苯的衍 生物之间通过 $\sigma$ 键连接起来, 分布在石墨烯的表面, 然 后再与叠氮基化合物通过点击反应，对石墨烯进行表面 点击功能化改性. 芳胺类化合物通过自由基反应，以共 价键的方式连接到石墨烯上, 从而设计改变石墨烯的化 学性能和电学性能已经成为一种通用的石墨烯功能化 改性的方法.

2011 年, Zhang 等 ${ }^{[122]}$ 首次报道了在石墨烯的表面, 通过点击化学制备了具有光电流响应的石墨烯光敏功 能纳米复合材料. 首先, 使用 4-(三甲基硅烷基)乙炔基 苯胺的芳基重氮盐和石墨烯片层(GS)在 $60{ }^{\circ} \mathrm{C}$ 下反应 48 $\mathrm{h}$ 生成化合物(记作 T-GS); 然后用氟化四丁基铵除去保 护基(三甲基硅烷基), 并使乙炔基露出来, 得到炔基化 石墨烯 $(\mathrm{G}-\mathrm{C} \equiv \mathrm{CH})$; 再分别与四苯基卟啉锌的叠氮化合 物 $\left(\mathrm{ZnP}-\mathrm{N}_{3}\right)$ 和钉-2,2'-联吡啶-邻菲罗啉衍生物的配合物 的叠氮化合物 $\left(\mathrm{RuP}-\mathrm{N}_{3}\right)$ 进行点击反应, 分别生成化合物 ZnP-GS 和 RuP-GS, 如图 10 所示. 在周期性开/关控制 光照下, 涂在 ITO 上的 ZnP-GS 和 RuP-GS 薄膜有典型 的光电效应, 并且两个样品上的可逆的上升/衰减光电
效应对应于开/关的照射节奏. 在光照条件下，电子分别 从 $\mathrm{ZnP}$ 和 $\mathrm{RuP}$ 转移到 $\mathrm{GS}$ 上, 观测到 $\mathrm{ZnP}-\mathrm{GS}$ 的电流大小 为 $0.31 \mu \mathrm{A} \cdot \mathrm{cm}^{-2}$, 而 $\mathrm{RuP}-\mathrm{GS}$ 的电流大小为 $0.56 \mu \mathrm{A} \bullet \mathrm{cm}^{-2}$. 经多次开/关照射 ZnP-GS 和 RuP-GS 均显示了光稳定性, 因此可能用来制备光能转化器和光敏器件.

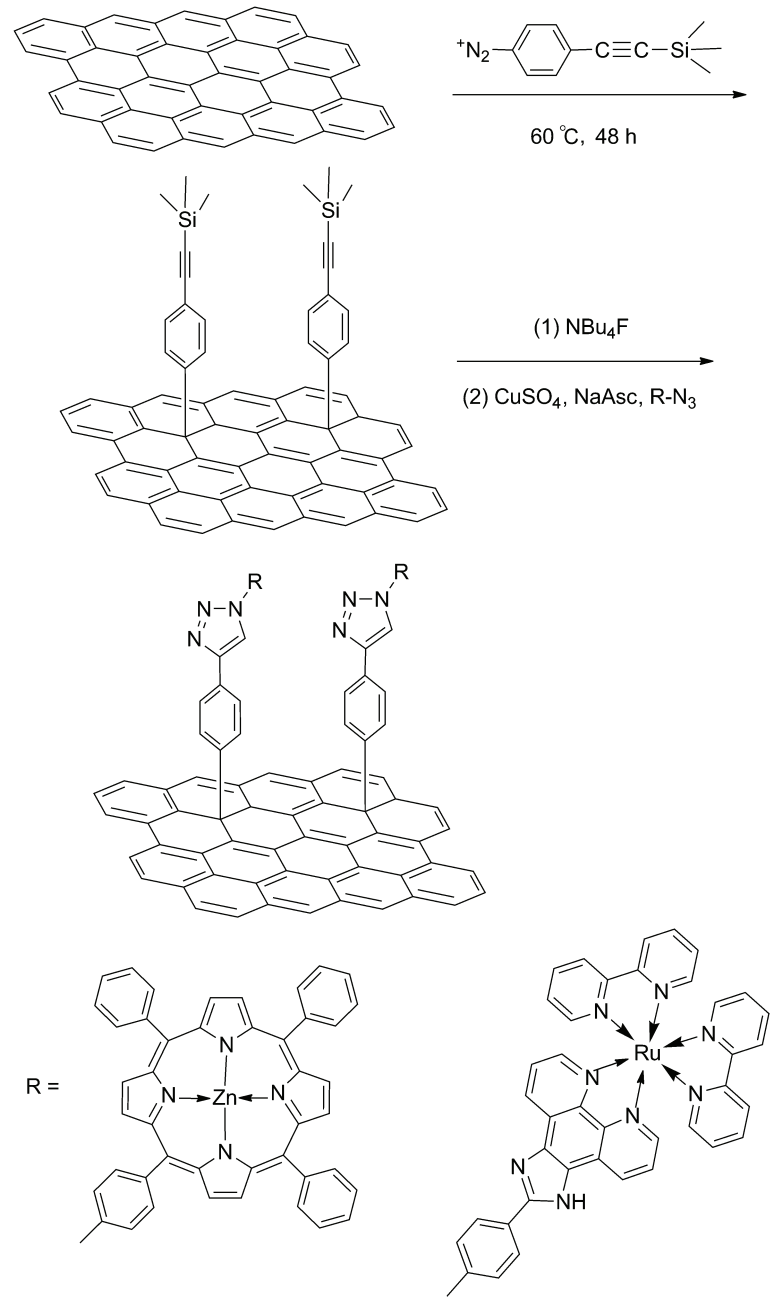

图 10 通过点击化学修饰石墨烯的合成路线

Figure 10 The synthesis route for the chemical modification of GS via "click" chemistry

Salavagione 等 ${ }^{[123]}$ 通过点击化学将 1,4-二酮吡咯并 吡咯(DPP)连接在石墨烯的表面制备了具有光电活性纳 米复合材料. 首先制备了不对称的叠氮化 1,4-二酮吡咯 并吡咯(DPP)衍生物, 然后将 4-(三甲基硅烷基)乙炔基 苯胺的芳基重氮盐和 $\mathrm{G}$ 在 $60{ }^{\circ} \mathrm{C}$ 下反应 $48 \mathrm{~h}$, 再经过去 保护基后, 得到炔基化的石墨烯 $(\mathrm{G}-\mathrm{C} \equiv \mathrm{CH})$, 最后与叠 氮基的 DPP 衍生物(DPP- $N_{3}$ ) 通过点击反应得到由 DPP 功能化改性的石墨烯复合物(G-DPP), 如图 11 所示. 经 过循环伏安法(CV)分别对 DPP 和 G-DPP 进行测试, 结 果显示: 改性后的 G-DPP 明显地改变了 DPP 的还原带 的位置, 阴极电位明显减少了 (超过 $900 \mathrm{mV}$ ), 说明了 DPP 与 G 之间有强烈的相互作用. 而关于复合物 G-DPP 的光物理行为和光伏性能正在进一步的探讨和研究中. 

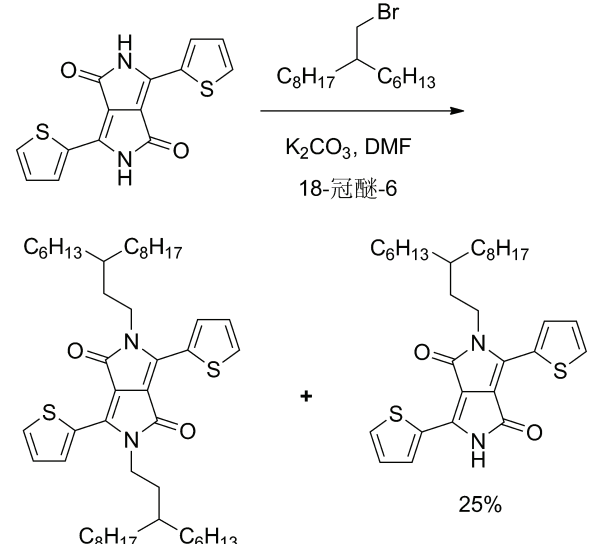

$33 \%$

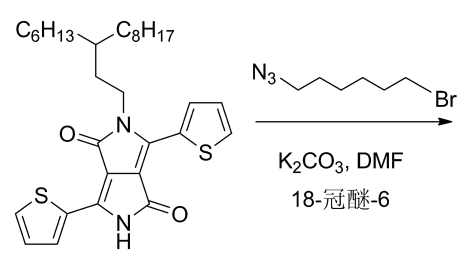

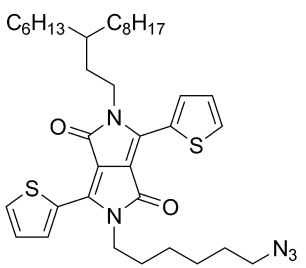

$36 \%$

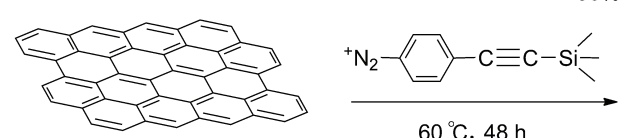

$60{ }^{\circ} \mathrm{C}, 48 \mathrm{~h}$
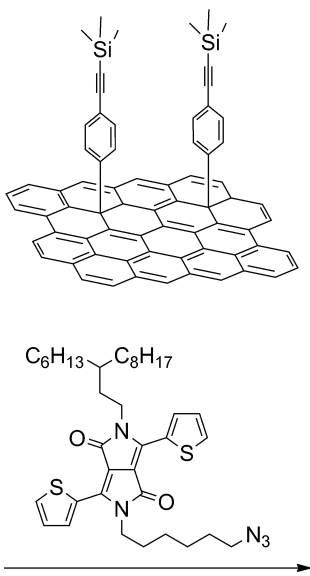

$\left[\left(\mathrm{CH}_{3} \mathrm{CN}\right)_{4} \mathrm{Cu}\right]^{+} \mathrm{PF}_{6}$ $50{ }^{\circ} \mathrm{C}, 3 \mathrm{~d}$
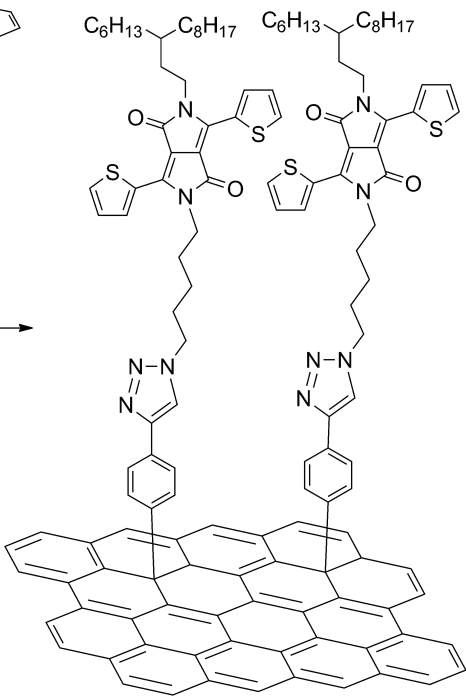

图 11 DPP 的叠氮功能化和 DPP-G 点击反应的合成路线

Figure 11 The synthesis route for azido-functionalization of DPP and click reaction for DPP-G

Strano 等 ${ }^{[124]}$ 将聚乙二醇羧酸点击在石墨烯的表面, 制备了水分散性较好的石墨烯纳米复合材料. 他们分别 使用了自制的溶液相石墨烯(SP-G)和化学气相沉积法
石墨烯(CVD-G)作为原料，分散在 $2 \%$ 的胆酸钠(作为表 面活性剂)水溶液中, 与 4-炔丙氧基重氮苯四氟硼酸盐 在 $45{ }^{\circ} \mathrm{C}$ 下搅拌 $8 \mathrm{~h}$, 生成 4-炔丙氧基苯基石墨烯 $(\mathrm{G}-\mathrm{C} \equiv$ $\mathrm{CH})$. 然后，再与短链的叠氮基聚乙二醇羧酸进行点击 化学反应, 如图 12 所示. 此方法较为灵活方便的设计改 变连接石墨烯的功能化改性基团，可能将来用于制备石 墨烯的复合材料和生物传感器.
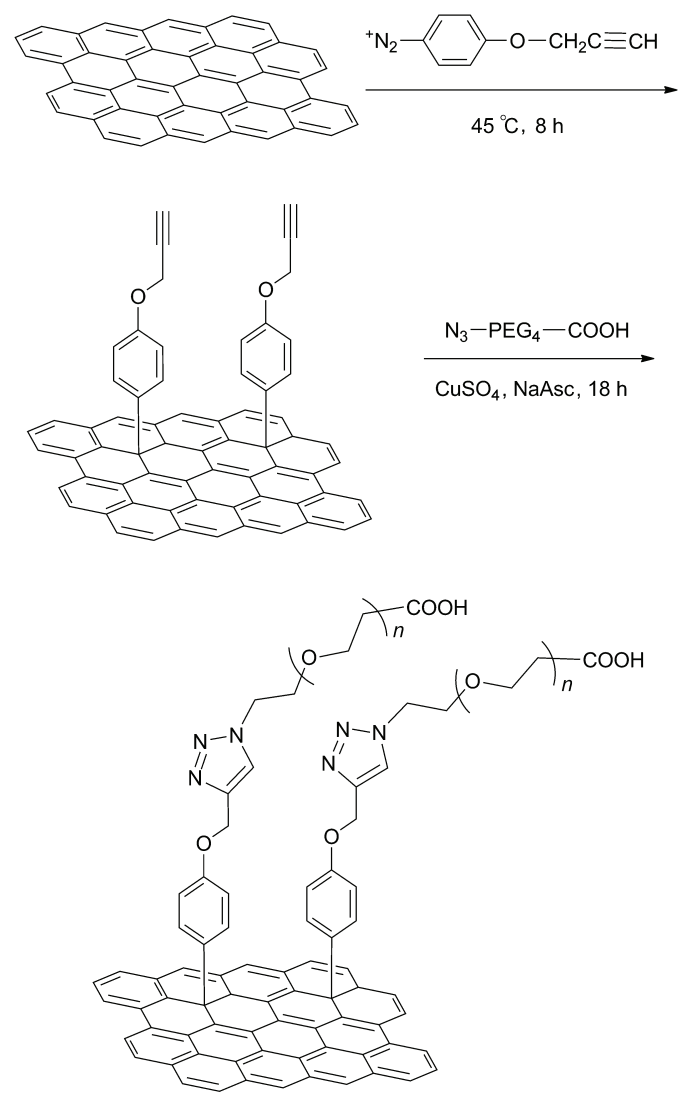

图 12 石墨烯的重氮化和点击反应功能化的合成路线

Figure 12 The synthesis route for diazonium reaction and click chemistry functionalization on graphene sheets

Zhao 等 ${ }^{[125]}$ 在石墨烯的表面上点击了链转移试剂, 通过可逆加成一断裂链转移聚合(RAFT)制备了石墨烯聚 $(N$-异丙基丙烯酰胺)分子刷. 首先，将对氨基苯甲酸 炔丙酯的重氮盐和还原氧化石墨烯(RGO)在室温下摚拌 过夜，反应得到炔基功能化的石墨烯 $(\mathrm{G}-\mathrm{C} \equiv \mathrm{CH})$, 然后 与含叠氮基的 S-1-十二烷基-S'-( $\alpha, \alpha^{\prime}$-二甲基- $\alpha$ "-3-叠氮 基-1-丙基乙酸酯)三硫代碳酸酯(RAFT)通过点击化学反 应得到 RGO-RAFT 的链转移试剂(CTA). 最后将 RGO-RAFT 的链转移试剂(RGO-RAFT CTA) 与 $N$-异丙 基丙烯酰胺单体(NIPAM)聚合得到石墨烯功能化改性的 RGO-PNIPAM, 如图 13 所示. 其中, PNIPAM 是一种具 有低临界共溶温度(LCTS)的热敏聚合物. 经微量热仪 (Micro-DSC)测试结果显示, RGO-PNIPAM 纳米复合材 料在水分散液中的 LCTS 为 $33.2{ }^{\circ} \mathrm{C}$, 当温度高于 LCTS 时，破坏了 PNIPAM 中亲水基团与分子间的氢键，而形 
成分子内氢键, 于是 RGO-PNIPAM 沉淀析出; 当温度 低于 LCTS 时, PNIPAM 又重新与水分子形成氢键, 于是 RGO-PNIPAM 又可以迅速地分散到水中. 他们还指出 了, 点击化学和 RAFT 聚合可广泛地应用于氧化石墨 烯-聚合物纳米复合材料的合成与制备.
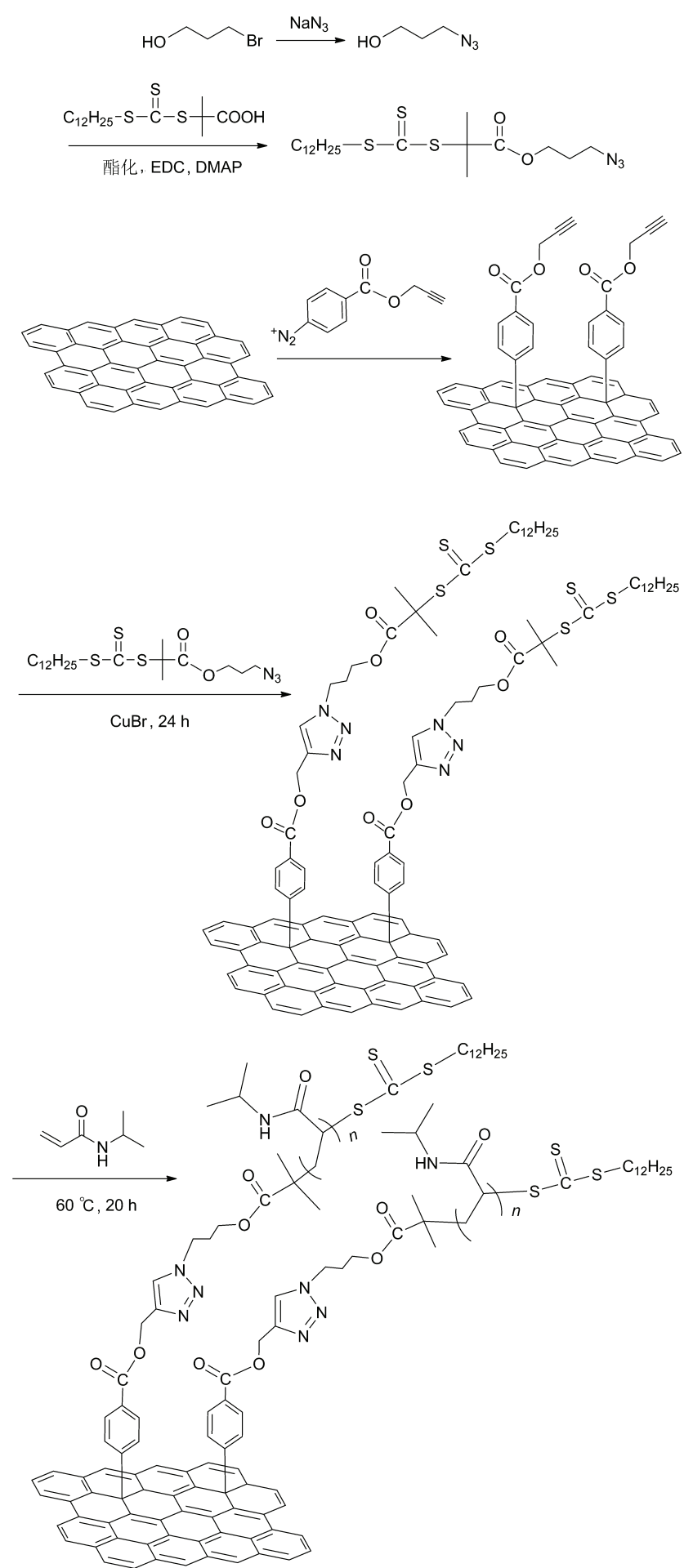

图 13 RAFT CTA 改性的 RGO 和 NIPAM 在 RGO 面上的 RAFT 原位 聚合的合成方法

Figure 13 The synthesis of the RAFT CTA-modified RGO, and in situ RAFT polymerization of NIPAM on the surfaces of RGO sheets
2012 年, Salavagione 等 ${ }^{[103]}$ 通过点击化学将聚芴类 高分子化合物连接在石墨烯的表面，并研究了石墨烯对 聚芴的荧光猝灭效应. 在他们的报道中，通过重氮化合 物完成了对石墨烯的炔基化修饰，这种修饰改性的方法 比重氮盐方法简单方便. 首先, 在 $80{ }^{\circ} \mathrm{C}$ 下将 4-乙炔基 苯胺与亚硝酸异戊酯作用, 生成重氮化合物后, 再与 $\mathrm{G}$ 反应过夜，得到炔基化的石墨烯 $(\mathrm{G}-\mathrm{C} \equiv \mathrm{CH})$. 然后再与 叠氮基的共轭高聚物 9,9-二已基芴和 9,9-双-(6-叠氮基 己基荡)交替共聚物(PFA-N 3 ) 通过点击化学得到石墨烯 的功能化改性化合物 PFA-G, 如图 14 所示. 在 PFA-G 组 件中, G 本身具有较好的电子迁移率，而 PFA 则是一个 较好的共轭共聚物电子供体. 基于光致发光效应，该组 件要求快速的电荷分离, 并实现最小程度上的电子-空 穴的重新复合, 而石墨烯可以将产生的电荷进行很好的 传输, 从而使光致发光的发射光谱有所减弱. 但外部环 境对 PFA-G 组件的光致发光过程中的电子吸收和发射 有着显著的影响. 在溶解性较好的溶剂中, PFA 的分子 链较为均匀的分散在溶剂中, 形成较为舒展的分子刷形 状. 而在溶解性较差的溶剂中, PFA 与 $\mathrm{G}$ 之间通过 $\pi-\pi$

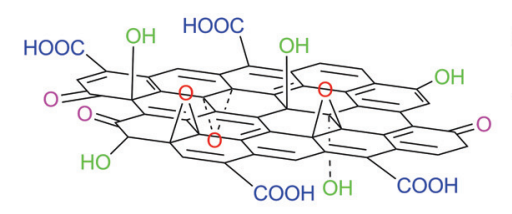

(1) $\mathrm{NH}_{2} \mathrm{NH}_{2} \cdot \mathrm{H}_{2} \mathrm{O}$

$90{ }^{\circ} \mathrm{C}, 1 \mathrm{~h}$

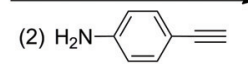

$0=\mathrm{N}^{\mathrm{O}} \sim \mathrm{O}^{\circ} \mathrm{C}$
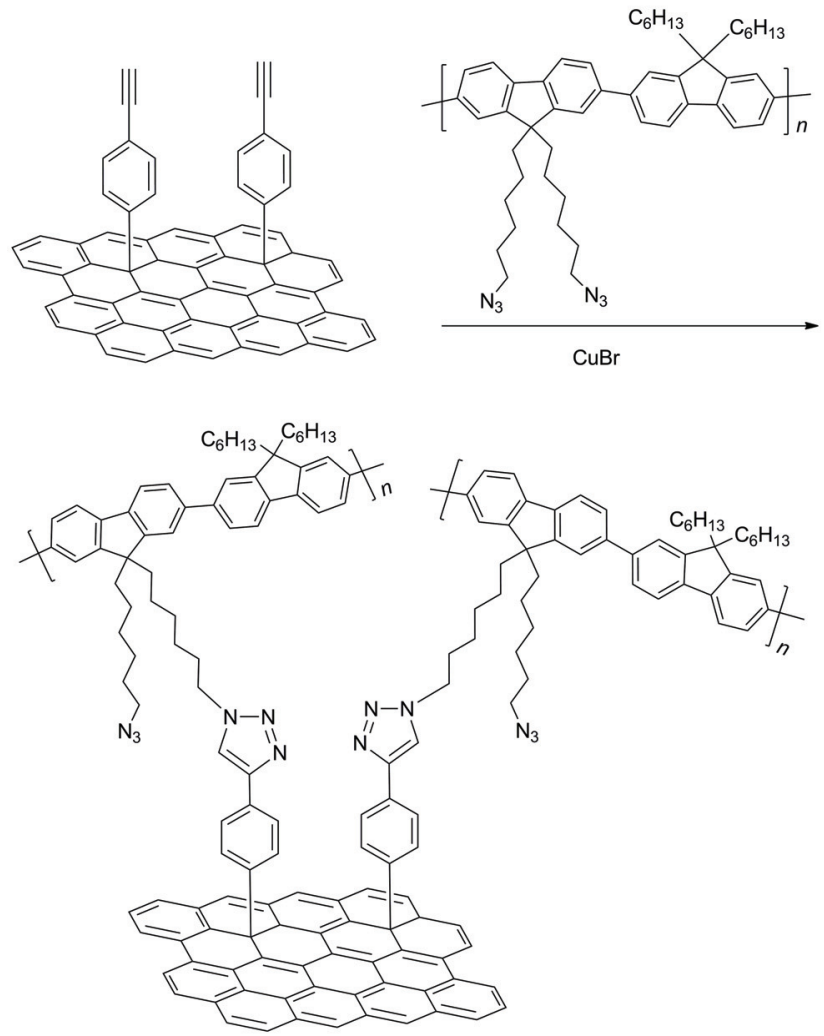

图 14 通过表面点击功能化合成 PFA-G 的路线

Figure 14 The synthesis route for the PFA-G on the surface of G with click chemistry 
堆积作用而平铺在 $\mathrm{G}$ 的表面上. 因此, 在不同溶剂环境 中 PFA-G 的结构也不同, 从而影响其光致发光. PFA-G 的光致发光在溶剂 $o-\mathrm{DCB}$ (邻二氯苯)和 $\mathrm{NMP}(N$-甲基吡 咯烷酮)中稍有降低, 但在 DMF 中几乎完全消失. PFA 与 $\mathrm{G}$ 之间的相互作用使得聚合物 PFA 的 HOMO 轨道的 能级升高. 因此, 在循环伏安法 $(\mathrm{CV})$ 测试中显示, 与 PFA 相比 PFA-G 则移动到了较低的正电位; 而这可从在 UV-vis 吸收光谱中 PFA-G 相对于 PFA 蓝移的吸收光谱 得到佐证. PFB(PFA 的前体, 溴化聚荡)具有良好的光致 发光效果, PFA-G 则作为一个猝灭剂, 随着浓度的增加, 复合材料的光致发光强度呈线性下降，从而说明了 PFA-G 与 PFB 之间有较强的相互作用. 他们还指出, 通 过点击反应对一些材料进行富有想象力的设计和改性, 从而制备出具有较低带隙和较高载流子迁移率的更加 适用于太阳能电池的材料.

Huang 等 ${ }^{[126]}$ 采用 “接枝到” ( “grafting to”) 和 “接 枝于” ( “grafting from”) 两种灵活高效的接枝方法, 通 过可逆的链转移和点击化学制备功能化改性的石墨烯 分子刷. 在整个反应过程中, 也是通过重氮化合物完成 了对石墨烯的炔基化修饰. 在 $80{ }^{\circ} \mathrm{C}$ 下, 首先将 4-炔丙
氧基苯胺与亚硝酸异戊酯作用，生成重氮化合物后，再 与 $\mathrm{G}$ 反应 $0.5 \mathrm{~h}$, 得到炔基化的石墨烯 $(\mathrm{G}-\mathrm{C} \equiv \mathrm{CH})$, 然后 采用 “接枝到” 和 “接枝于” 两种接枝方法制备功能 化改性的石墨烯分子刷。“接枝到” 法, 首先通过 RAFT 链转移试剂分别与 St, MMA, MAA, 4VP, DMA 等 5 种单体聚合得到含叠氮基功能化高分子, 然后与含炔 基的石墨烯进行点击反应得到功能化改性的石墨烯，如 图 15 所示. “接枝于” 法, 首先通过点击反应合成含 有 RAFT 链转移试剂的功能化石墨烯, 再分别与 St, MMA, MAA, 4VP, DMA 等 5 种单体进行自由基聚合得 到功能化改性的石墨烯, 如图 16 所示. 石墨烯分子刷以 共价键形式接入的各种功能化高分子有水溶性的、油溶 性的、酸性的、碱性的、极性以及非极性的等等. 然而, “接枝到” 和 “接枝于” 两种方法具有互补的优缺点. “接枝到” 法所接枝的分子链长度有限, 有较大的分子 链接枝密度和较好的可加工性, 但溶解性较差. “接枝 于” 法所接枝的分子的分子量较大，分子链的接枝密度 较小, 有较好的溶解性, 但可加工性较差. 他们还指出, 这些多功能的接枝方法为制备独特性能的高分子功能 化石墨烯材料开辟了新的领域.<smiles>CC(C)(C)SC(=O)c1ccccc1</smiles>

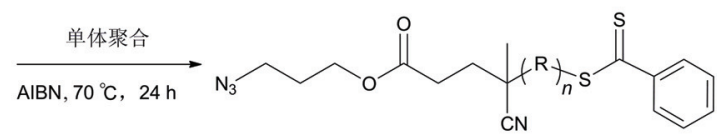<smiles>C=Cc1ccncc1OC(=O)C(=C)C(=O)OC(C)C(=C)C</smiles><smiles>CC(C)COCCN(C)C</smiles>

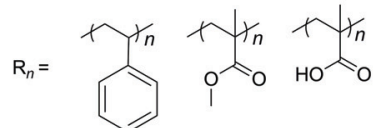<smiles>CC(C)CC(=O)OCCN(C)C</smiles>

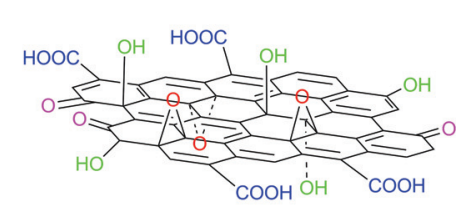

(1) $\mathrm{NH}_{2} \mathrm{NH}_{2} \cdot \mathrm{H}_{2} \mathrm{O} \quad 100{ }^{\circ} \mathrm{C}, 1 \mathrm{~h}$<smiles>C#CCOc1ccc(N)cc1</smiles>
$\mathrm{O}=\mathrm{N}^{\mathrm{O}} \sim \mathrm{C} 80^{\circ} \mathrm{C}, 0.5 \mathrm{~h}$

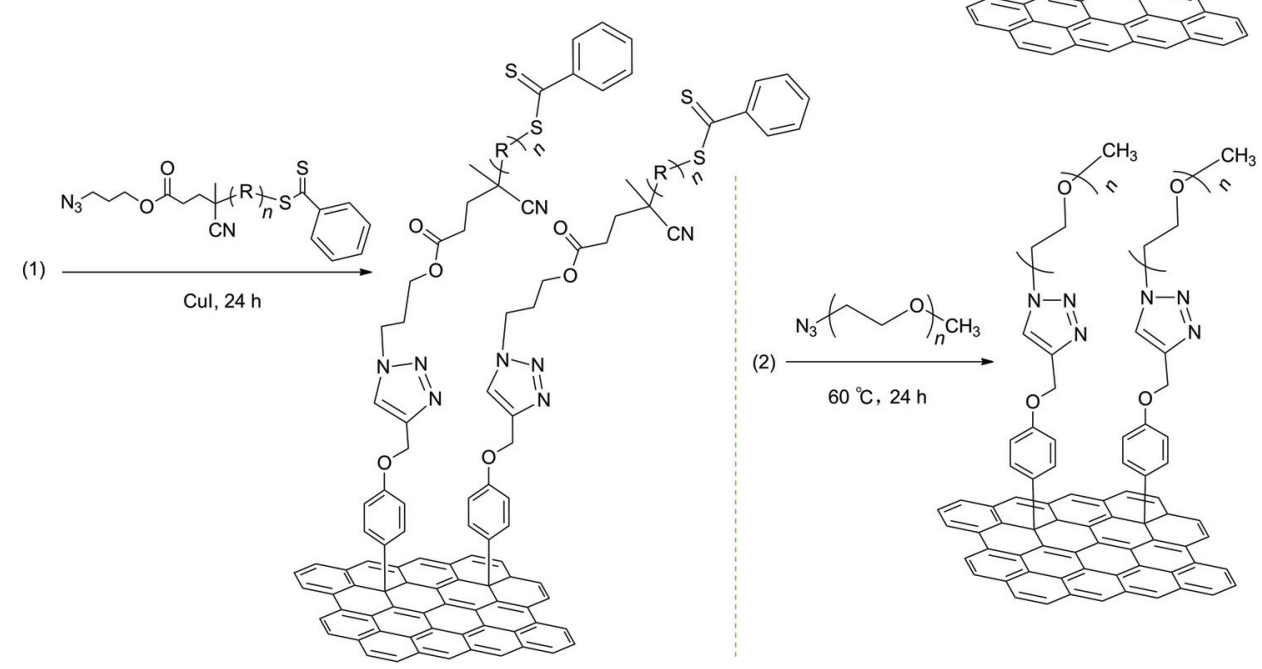

图 15 PEG-FG 和 $\mathrm{R}_{n}$-FG 通过 “接枝到” 的合成路线

Figure 15 Synthesis route for PEG-FG and $\mathrm{R}_{n}-\mathrm{FG}$ by "grafting to" 


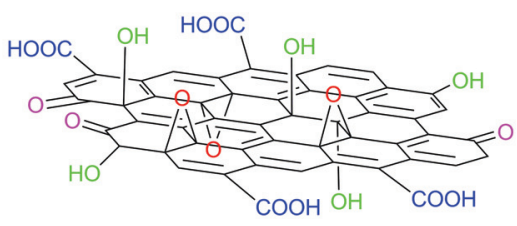

(1) $\mathrm{NH}_{2} \mathrm{NH}_{2} \cdot \mathrm{H}_{2} \mathrm{O} \quad 100{ }^{\circ} \mathrm{C}, 1 \mathrm{~h}$
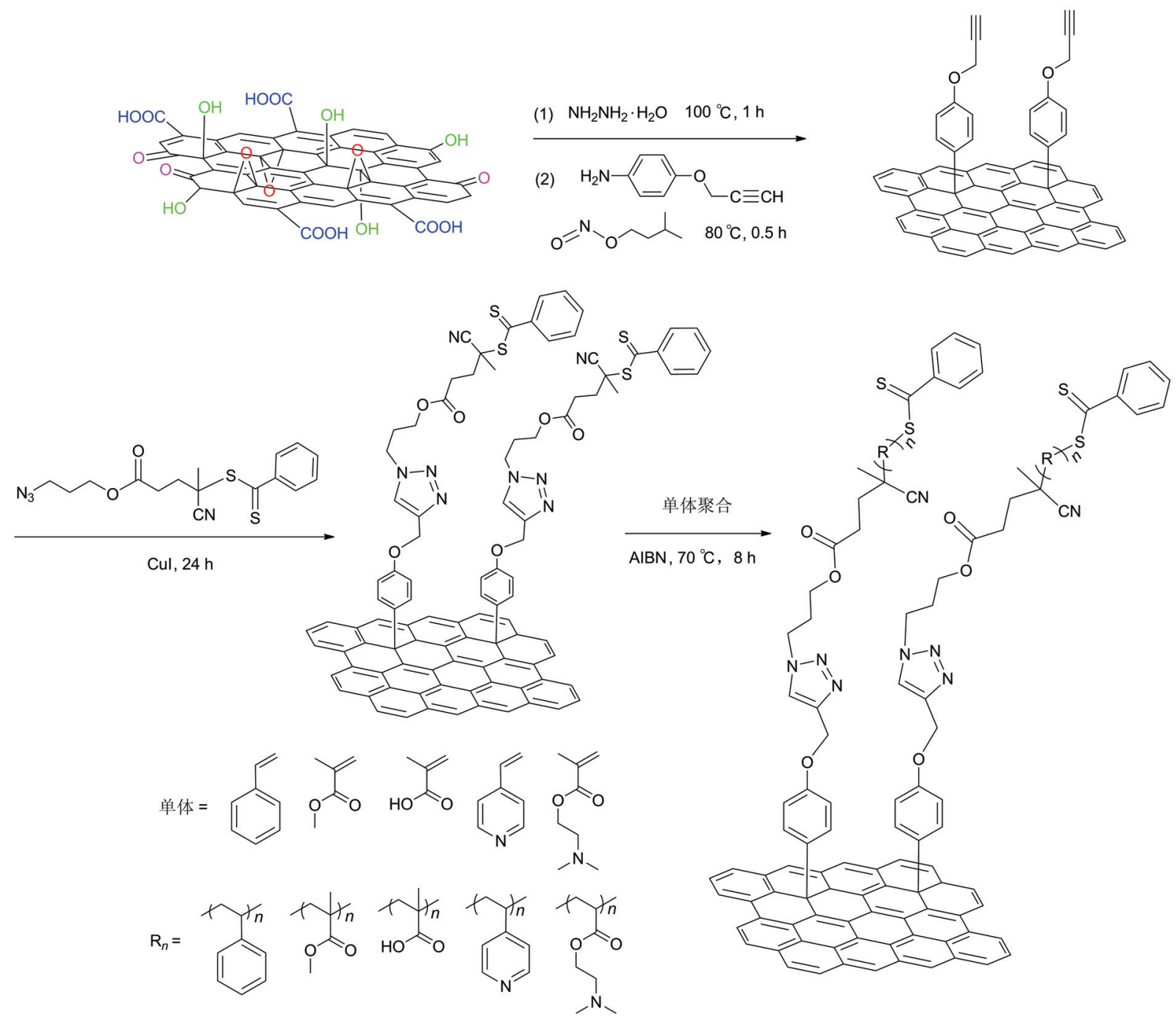

图 $16 \mathrm{R}_{n}$-FG 通过 “接枝于” 的合成路线

Figure 16 Synthesis route for $\mathrm{R}_{n}-\mathrm{FG}$ by "grafting from"

由上述文献总结可知, 石墨烯作为反应底物, 与含 有炔基的芳香胺类化合物的重氮盐(或重氮化合物)反 应, 对石墨烯进行表面点击功能化改性, 具体步骤可分 为: (1)重氮盐(或重氮化合物)经过脱氮气后形成自由基 与石墨烯加成反应, 生成炔基化的石墨烯 $(\mathrm{G}-\mathrm{C} \equiv \mathrm{CH})$. (2)炔基化的石墨烯与端基为叠氮基的功能化改性分子 通过化学点击反应, 对石墨烯进行功能化改性. (3)某些 通过点击反应合成含有 RAFT 链转移试剂的功能化石墨 烯, 然后再与不饱和单体进行自由基聚合得到功能化改 性的石墨烯.

\subsection{3 通过 D-A [4 + 2]反应对石, 墨烯进行表面点击功能 化改性}

在还原石墨烯的边缘还有部分羧基、羰基、酯基等 吸电子残基, 因此石墨烯上的 $\mathrm{C}=\mathrm{C}$ 双键可以作为亲双 烯体, 在加热的条件下可与其他双烯体进行 D-A [4+2] 环加成反应. 通过 D-A [4+2]反应对石墨烯进行表面点
击功能化改性, 这是一个极具优越性的方法.

2012 年, Weng 等 ${ }^{[127]}$ 首次报道了石墨烯在无催化剂 的情况下, 通过 D-A [4+2]点击反应制备了具有较好分 散性的石墨烯功能化复合物. 首先, 将环戊二烯基聚乙 二醇甲醚(mPEG-Cp) 和 $\mathrm{RGO}$ 超声处理 $10 \mathrm{~min}$, 然后分 别在常温和 $80{ }^{\circ} \mathrm{C}$ 不加任何催化剂的条件下搅拌 $24 \mathrm{~h}$, 首次只通过一步 D-A [4+2]点击反应成功将环戊二烯基 聚乙二醇甲醚( $\mathrm{mPEG}-\mathrm{Cp}$ ) 接枝到 $\mathrm{RGO}$ 上, 产率分别为 $16.7 \%$ 和 $21.8 \%$, 如图 17 所示. 改性后的石墨烯显著提 高了在各种溶剂中的分散性, 其中在 DMSO、DMF、 NMP、THF、乙二醇、乙醇、水、丙酮、氯仿等溶剂中 的分散性较好; 但是在甲苯、乙醚和已烷中的分散性依 然较差. 此方法与其它点击功能化改性方法相比, 过程 较为简单, 条件较为方便温和, 显示出了极大的优越性. 他们正努力通过此方法来发展石墨烯和其他碳材料方 面有关自增㓞和自修复等机械响应的复合材料. 

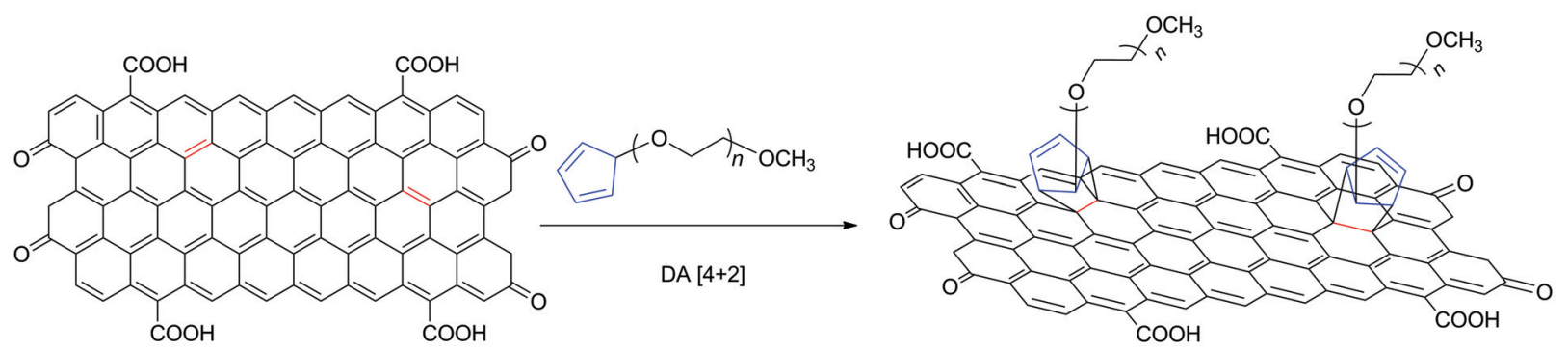

图 17 石墨烯和环戊二烯基封端的甲基聚乙二醇通过 D-A [4+2]的点击功能化合成路线

Figure 17 Synthesis route for the functionalization of graphene with mPEG-Cp by the Diels-Alder [4+2] "click" reaction

\section{3 非共价键作用的石墨烯点击功能化改性}

由于石墨烯与含有芳香基团的功能化小分子之间 存在 $\pi-\pi$ 堆积作用以及范德华力, 可以将带有芳香基团 的小分子牢牢地 “吸附” 在石墨烯的表面, 然后可通过 点击反应对石墨烯进行功能化改性. 它的特点是保持了 石墨烯原来的共轭结构、机械性能以及电化学性能, 而 且反应操作也较为简单方便, 但是非共价键结合的作用 力比较小, 而且功能化分子在石墨烯表面上分布的密度 也相对较小.

2012 年, Szunerits 等 ${ }^{[128]}$ 首次报道了通过非共价键 作用的石墨烯点击功能化改性. 在室温条件下, 用超声 波处理 GO 和含叠氮基的多巴胺衍生物的水悬浮液 $2 \mathrm{~h}$, 使得氧化石墨烯的还原和非共价键功能化同步进行, 并 得到衍生物 $\left(\mathrm{G} / \mathrm{DA}-\mathrm{N}_{3}\right)$, 然后与乙炔基的二茂铁通过化 学点击反应对石墨烯进行功能化改性, 如图 18 所示. 同 时, 也需要指出此方法对石墨烯的还原程度比较轻, 经 XPS 测试, GO 中的 $\mathrm{C} / \mathrm{O}$ 比值为 1.73 , 还原后的 RGO 中 的 $\mathrm{C} / \mathrm{O}$ 比值为 3.3 , 还是低于 Stankovich 等 ${ }^{[37]}$ 所报道的 由水合肼还原后的石墨烯的 $\mathrm{C} / \mathrm{O}$ 比值 10.3. 可喜的是, 他们得到了一个简单的、环境友好型的化学合成方法. 此方法开辟了新的前景, 不仅可以在比较温和的条件下 还原氧化石墨烯, 而且还可以制备较宽范围的氧化石墨 烯复合材料和化学传感器.

笔者认为, 多巴胺衍生物与还原氧化石墨烯之间的
作用不仅仅是范德华力和 $\pi-\pi$ 堆积作用, 而且多巴胺中 苯环上的两个羟基与还原氧化石墨烯表面上残余的环 氧基和羟基之间可以形成氢键，这对复合物石墨烯一多 巴胺的稳定性有着重要的贡献.

Szunerits 等 ${ }^{[129]}$ 在 2012 年报道了通过使用四硫富瓦 烯 ${ }^{[130]}$ 又进一步拓展了氧化石墨烯的还原与功能化同步 进行的研究方法. 在室温条件下, 将 $\mathrm{GO}$ 与叠氮基四硫 富瓦烯(TTF- $\left.\mathrm{N}_{3}\right)$ 的混合物通过超声处理 $3 \mathrm{~h}$ 后, 得到还 原和功能化改性同步进行的纳米杂化的复合材料, 即通 过非共价键 $\pi-\pi$ 堆积作用形成的 TTF 修饰的还原氧化石 墨烯 $\left(\mathrm{G} / \mathrm{TTF}-\mathrm{N}_{3}\right)$, 经 XPS 测试 C/O 比值约为 10 , 比较接 近于 Stankovich 等 ${ }^{[37}$ 所报道的由水合肼还原后的石墨 烯的 $\mathrm{C} / \mathrm{O}$ 比值 10.3. 然后与 1-炔丙基- $\alpha$ - $D$-甘露糖 ${ }^{[131]}$ 通 过点击化学反应, 得到石墨烯功能化修饰的产物石墨 烯/TTF-甘露糖(G/TTF-Mannose), 如图 19 所示. 将涂在 ITO 玻璃上的 G/TTF- $N_{3}$ 薄膜通过 CV 测试显示, 具有独 特的电子结构和增强电子迁移的能力. 他们通过在 $\mathrm{Fe}\left(\mathrm{ClO}_{4}\right)_{3}$ 溶液中使用化学氧化法 ${ }^{[132]}$, 将 G/TTFMannose 氧化并使 TTF-Mannose 从 $\mathrm{G}$ 的表面上释放脱 落; 另外, 又通过缺电的环双(百草枯-1,4-亚苯基)阳离 子 $\mathrm{CBPQT}^{4+}$ 与富电的 TTF-Mannose 之间形成主-客体 的分子组装体系, 使 TTF-Mannose 分子从 G/TTFMannose 纳米复合材料中释放出来, 如图 20 所示. 经 UV-vis 吸收测试，它们的释放率分别达到 $65 \%$ 和 $100 \%$.
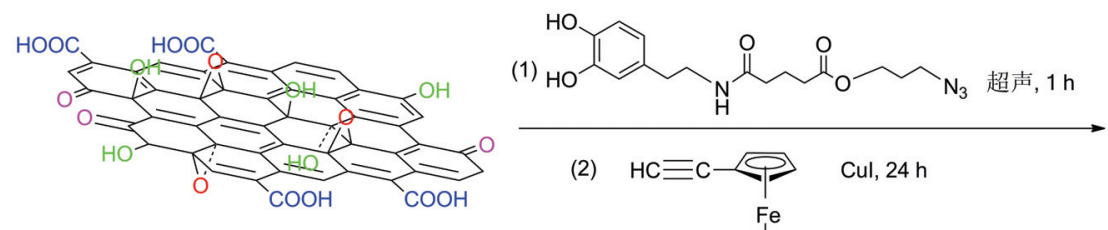

(2) $\mathrm{HC} \equiv \mathrm{C}-\mathrm{Cul}, 24 \mathrm{~h}$
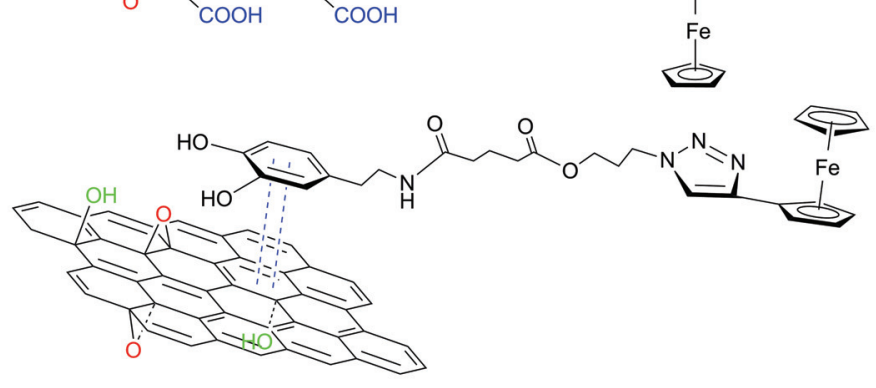

图 18 使用多巴胺衍生物对氧化石墨烯还原和功能化同步进行的示意图

Figure 18 Schematic illustration of the reduction and functionalization of graphene oxide with dopamine derivaives in one step 

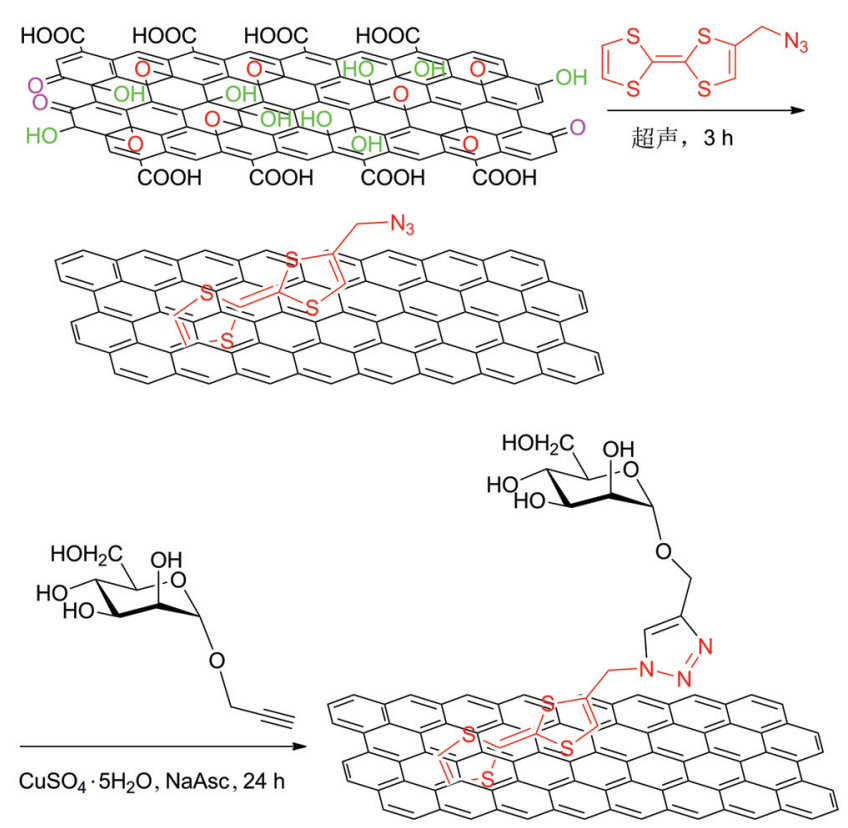

图 19 氧化石墨烯的还原和功能化同步进行得到 G/TTF-甘露糖复合 物的示意图

Figure 19 Schematic illustration of the reduction and functionalization of GO to the G/TTF-mannose in one step

他们还指出这项研究的意义在于, 通过石墨烯与四硫富 瓦烯-聚糖结合所形成的分子 “切换” 器件可能涉及到 通过多价键来实现控制聚糖与蛋白质(如细菌, 凝集素 或抗体)之间相互作用. (a)
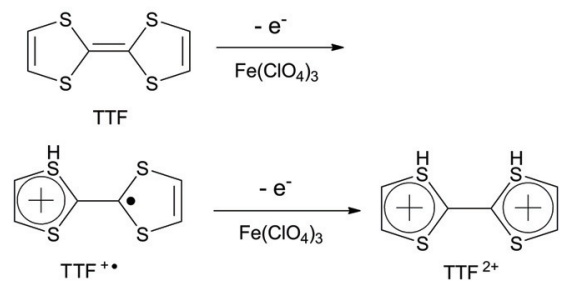

(b)

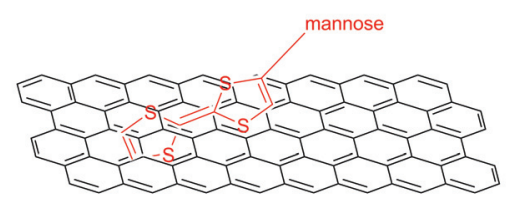

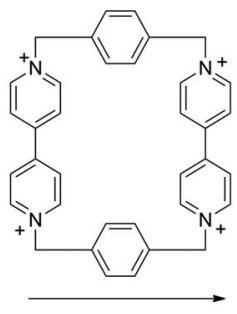

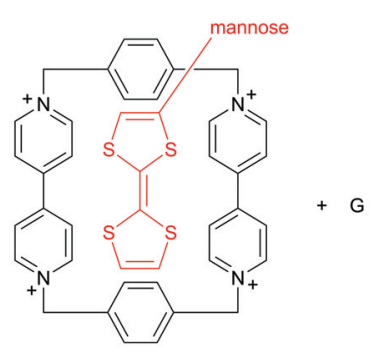

图 20 (a) 通过对 $\mathrm{TTF}^{[130]}$ 化学氧化成 $\mathrm{TTF}^{+}$和 $\mathrm{TTF}^{2+}$ 的示意图. (b) 通 过加入 $\mathrm{CBPQT}^{4+}$ 后由 $\mathrm{G} / \mathrm{TTF}$-甘露糖释放得到 TTF- 甘露糖的示意图 Figure 20 (a) Scheme of the chemical oxidation of $\mathrm{TTF}^{[130]}$ to $\mathrm{TTF}^{+\cdot}$ and $\mathrm{TTF}^{2+}$ by $\mathrm{Fe}\left(\mathrm{ClO}_{4}\right)_{3}$. (b) Scheme of the release of TTF-mannose from $\mathrm{G} / \mathrm{TTF}$-mannose composite by addition of $\mathrm{CBPQT}^{4+}$
另外，还有一些文献报道了关于其它稠环芳香化合 物与石墨烯之间通过 $\pi-\pi$ 堆积作用对石墨烯进行功能化 改性. Lee 等 ${ }^{[133]}$ 设计并合成了基于四个萠单元为基底和 一个横向接枝的树枝状低聚醚而形成的两亲分子，通过 $\pi-\pi$ 堆积作用的非共价键结合在石墨烯表面上，形成夹 层结构, 如图 21 所示. 从石墨烯平面外突出的亲水性低 聚醚可促进石墨烯在水溶液中的分散, 并且分散溶液中 没有明显的沉淀和聚集，可以非常稳定的存在两个月. 同时, 石墨烯一两亲分子的结合物还显示了优异的电学 性能，可用来制备透明的柔性石墨电极.

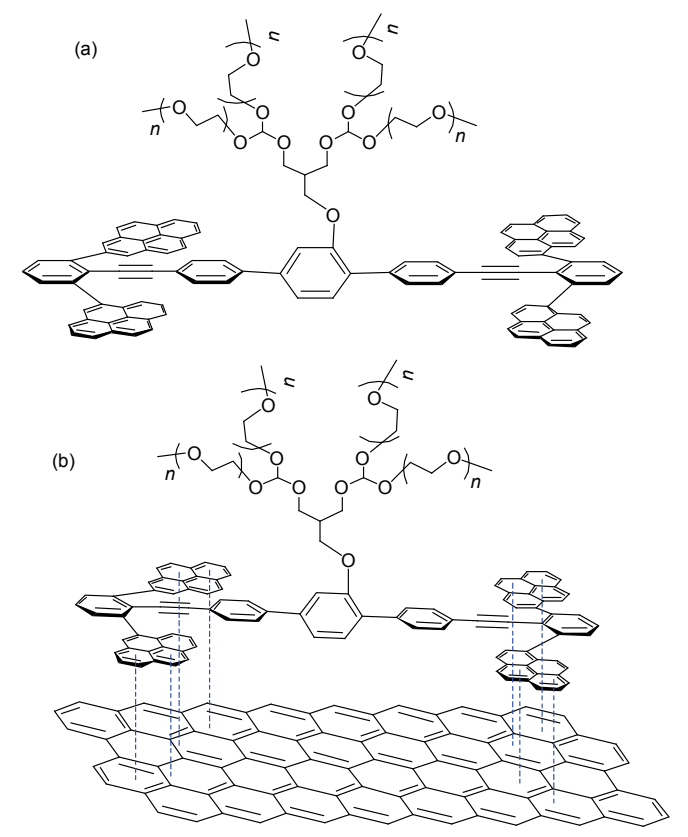

图 21 (a) 两亲化合物的化学结构; (b) 石墨烯与两亲化合物之间的 作用示意图

Figure 21 (a) Chemical structure of amphiphile compound; (b) Schematic illustration of the interaction between graphene and the amphiphile compound

Dichtel 等 ${ }^{[134]}$ 设计并合成了由三个萠为底座形成的 三脚架结构，与石墨烯之间通过 $\pi-\pi$ 堆积作用 “吸附” 在石墨烯的表面并支撑着一个远离石墨烯平面的具有 氧化还原活性的 $\operatorname{Co}(\mathrm{II})$-双-三联吡啶配合物结构，从而 对石墨烯进行表面功能化改性, 如图 22 所示. 并提出了 这种像针一样结合在石墨烯上的三脚架体系具有方位 控制和动力学稳定性，可以广泛地应用在整合化合物、 延展材料、光电材料、催化剂以及生物传感等领域.

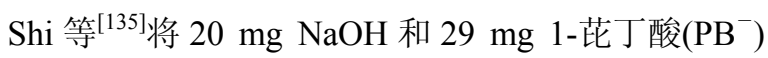
加入到 $20 \mathrm{~mL}$ 的 $\mathrm{GO}$ 分散液中, 在 $80{ }^{\circ} \mathrm{C}$ 下用水合肼还 原 $24 \mathrm{~h}$ 后，制备了由 $\mathrm{PB}^{-}$与 $\mathrm{RGO}$ 之间通过 $\pi-\pi$ 堆积作 用形成的非共价键功能化复合物 $\mathrm{PB}^{-}-\mathrm{G}$, 如图 $23 \mathrm{a}$ 所示. 该复合物在水中可以形成稳定的石墨烯分散液, 并且通 过过滤制备了导电率为 $2 \times 10^{2} \mathrm{~S} / \mathrm{m}$ 的大面积柔性石墨 烯薄膜. 后来又有报道, $\mathrm{Li}$ 等 ${ }^{[136]}$ 用 $10 \sim 20 \mathrm{mg}$ 的 $1,3,6,8-$ 
萠四磺酸钠(TPA)和 $1 \mathrm{mg}$ 的石墨粉混合在 $5 \mathrm{~mL}$ 的 $\mathrm{D}_{2} \mathrm{O}$ 中，在超声波作用下处理 $2 \mathrm{~h}$. TPA 通过 $\pi-\pi$ 堆积作用有 效的将石墨去角质形成石墨烯单分子膜后, 再分散到水 溶液中. 其中 $90 \%$ 的石墨烯片层为单层分子, 如图 $23 \mathrm{~b}$ 所示. 他们在研究过程中发现当石墨烯电子结构对称性 破坏后会促使带隙开放, 将来可能用来制备高通一断比 的石墨烯器件. 因此, 开辟了一个令人振奋的可能性, 即通过分子装饰来设计石墨烯的电子结构.

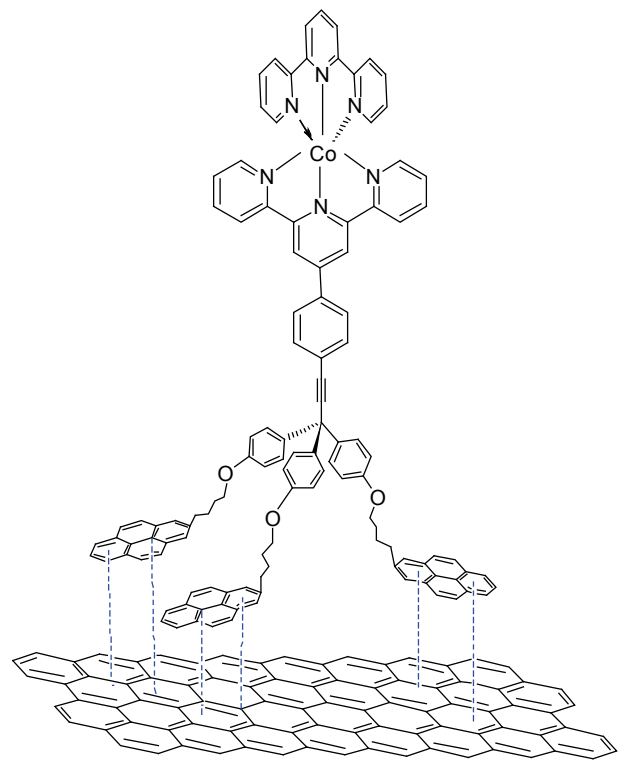

图 22 石墨烯与三脚架结合的结构示意图

Figure 22 Schematic illustration of the structure of the tripodal binder and Graphene
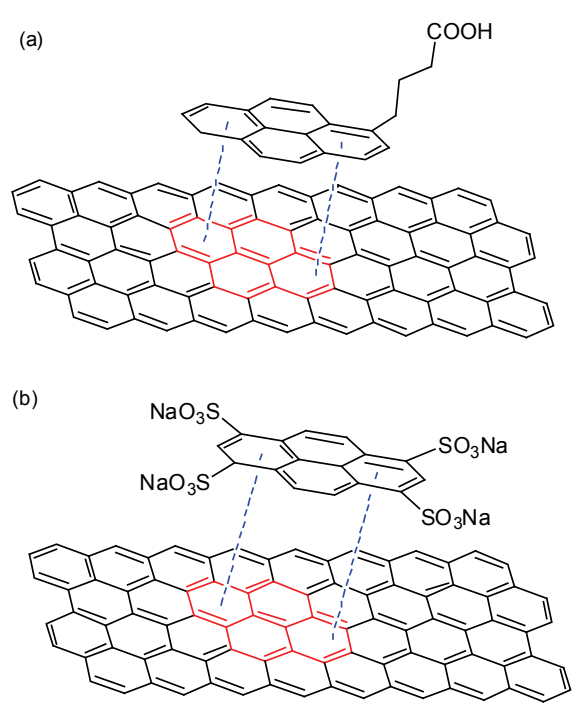

图 23 (a) 石墨烯与 1-萠丁酸 $\left(\mathrm{PB}^{-}\right)$之间的作用示意图; (b) 石墨烯与 $1,3,6,8$-萠四磺酸钠(TPA)之间的作用示意图

Figure 23 (a) Schematic illustration of the interaction between Graphene and the $\mathrm{PB}^{-}$; (b) Schematic illustration of the interaction between Graphene and the TPA

不仅仅是萠的衍生物可以和石墨烯之间有着稳定 的 $\pi-\pi$ 堆积作用, 还有菲等稠环芳香化合物与石墨烯之
间也存在着同样的 $\pi-\pi$ 堆积作用. Hersam 等 ${ }^{[137]}$ 报道了分 子半导体 3,4,9,10-芢四羧酸䣶(PTCDA)通过 $\pi-\pi$ 堆积作 用在 $\mathrm{SiC}$ 表面生长的外延石墨烯上经过分子自组装后形 成单层分子薄膜. 通过超高真空扫描隧道显微镜(STM) 测试显示，在室温下该分子具有长程有序的人字形排 列, 如图 24 所示. 而且, 这种完整的无缺陷的连续有序 的分子排列并未受到外延石墨烯表面上的点形的或线 形的缺陷以及底层 $\mathrm{SiC}$ 表面上的原子阶梯层边沿的影响 而形成了几百纳米的单层覆盖. 这种通过分子自组装形 成的有机功能化的外延石墨烯将来可用于制造分子级 别的电子器件和传感器. 还有其他一些文献 ${ }^{[138,139]}$, 也 报道了关于芢的衍生物与石墨烯之间通过 $\pi-\pi$ 堆积作用 形成了人字形排列的分子自组装.

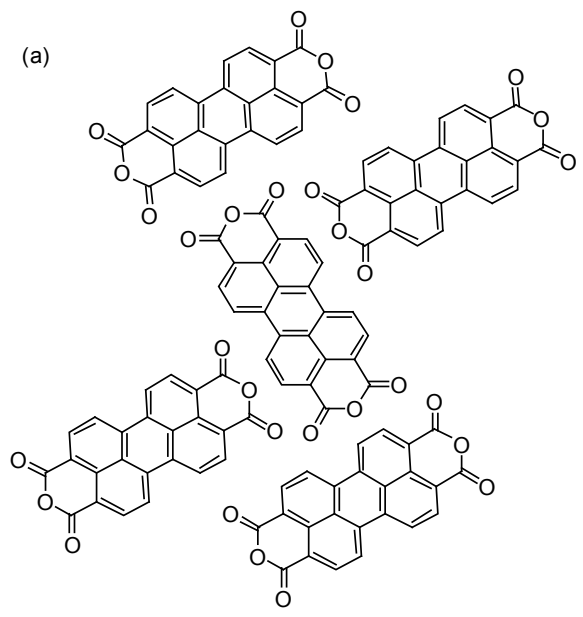

(b)

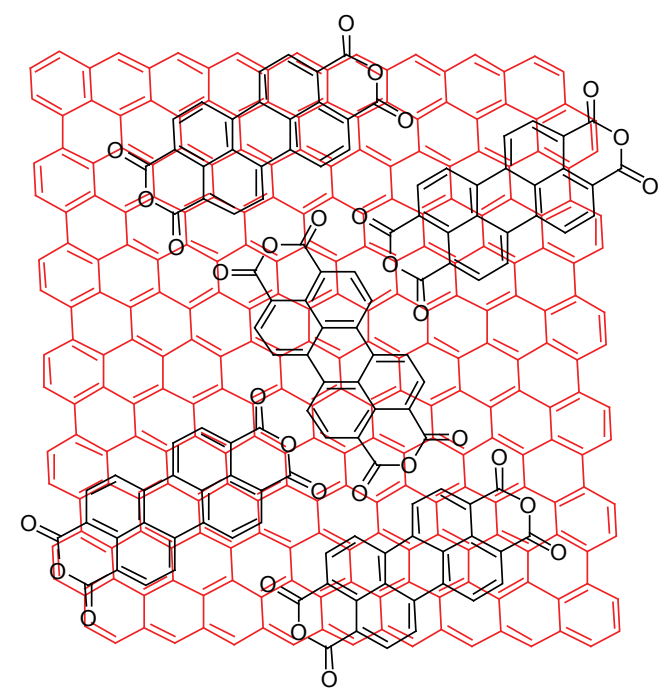

图 24 (a) 3,4,9,10-菲四羧酸酐的人字形排列; (b) PTCDA 与石墨烯之 间的作用示意图

Figure 24 (a) The herringbone arrangement of PTCDA; (b) Schematic illustration of the interaction between PTCDA and the graphene

Hirsch 等 ${ }^{[140]}$ 第一次证明萠酰亚胺类有机染料分子 (PBI)与石墨烯之间通过 $\pi-\pi$ 堆积作用(如图 25a 所示)而 使石墨烯溶解并形成了有机均相溶液, 因为在此之前这 
种情况只能在固体状态下观测到. 于是开辟了石墨烯在 有机溶剂中的非共价键功能化的新领域, 这将非常有益 于石墨烯在分子电子学领域的应用. Chen 等 ${ }^{[141]}$ 通过原 子转移自由基聚合(ATRP)制备了含聚丙烯酸甘油酯的 双菲酰亚胺衍生物(PBIPGA), 而 PBIPGA 与还原氧化石 墨烯(RGO)之间可以通过 $\pi-\pi$ 堆积作用形成分子自组装 后得到非共价键功能化的 RGO 聚合物复合材料 RGO-PBIPGA, 如图 25b 所示. RGO-PBIPGA 在水性介 质中具有良好的分散性, 并且经过对 3T3 成纤维细胞进 行体外细胞毒性测试, 显示了非常低的细胞毒性. 这种 纳米复合材料将来可以作为细胞成像和细胞内药物传 输等生物医学方面的探索应用. 还有一些文献 ${ }^{[142 ~ 144]}$ 报 道了关于 3,4,9,10-荘四羧酸 (PTCA)与石墨烯之间通过 $\pi-\pi$ 堆积作用形成了分子自组装.
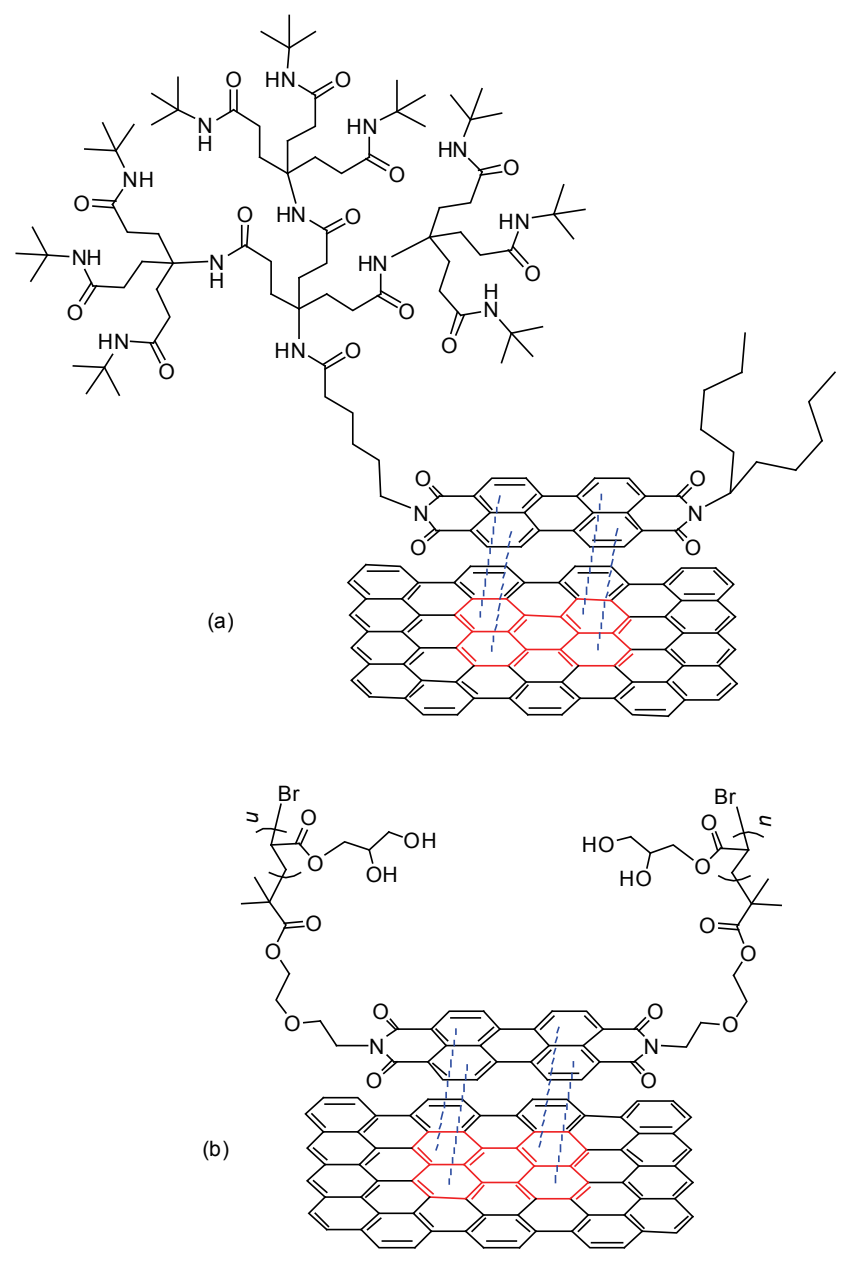

图 25 (a) PBA 与石墨烯之间的作用示意图; (b) PBIPGA 与石墨烯之 间的作用示意图

Figure 25 (a) Schematic illustration of the interaction between PBI and the graphene; (b) Schematic illustration of the interaction between PBIPGA and the graphene

$\mathrm{Niu}$ 等 ${ }^{[145,146]}$ 先后报道了石墨烯与 $3,4,9,10$-菲四羧 酸(PTCA)和 $N, N$-双-(1-氨基丙基-3-丙基咪唑盐)
$3,4,9,10$ - 菲四羧酸二酰亚胺(PDI)通过 $\pi-\pi$ 堆积作用后, 再与单链 DNA 作用并使单链 DNA 固定在石墨烯上, 然 后与它的互补 DNA 单链结合并形成双螺旋结构. 这种 方法将来可用于 HIV-1(人类免疫缺陷病毒, 即艾滋病病 毒)基因序列的检测.

由上述文献研究表明，萠与花等稠环芳香化合物的 衍生物和石墨烯之间有着稳定的 $\pi-\pi$ 堆积作用, 通过分 子自组装形成稳定的非共价键改性的化合物. 通过非共 价键作用对石墨烯进行功能化改性，是一种简单方便 的、环境友好型的改性方法，是对石墨烯功能化改性的 一个重要的合成方法和改性手段. 笔者认为萠(及其衍 生物)和菲(及其衍生物)以及其它稠环芳香化合物 ${ }^{[147]}$ 的 衍生物与石墨烯之间可以形成 $\pi-\pi$ 堆积作用, 然后通过 点击化学反应实现对石墨烯的功能化改性. 这也将成为 石墨烯点击功能化改性的一个重要方向, 目前尚未见到 这方面的相关报道.

\section{4 石墨烯点击功能化改性方法及意义}

通过点击化学对石墨烯进行功能化改性, 在石墨烯 复合材料的化学合成上具有重大的战略意义. 笔者根据 上述相关文献对石墨烯点击功能化改性的合成方法以 及反应过程进行归纳总结, 其中包括对石墨烯或者氧化 石墨烯的边缘和表面上常用的点击功能化改性前处理 方法和反应条件, 同时还介绍了相应的功能化连接分子 的合成方法以及反应条件，并简要地说明石墨烯点击功 能化改性后的纳米复合材料的功能特性以及应用前景, 见表 2 .

由表 2 可知, 在对石墨烯和氧化石墨烯点击功能化 改性的设计和合成操作过程中，根据功能化分子本身的 特性和溶解性来选择对其进行炔基化或者叠氮基化，然 后对石墨烯或者氧化石墨烯进行相应地叠氮基化或者 炔基化, 通过点击反应将两部分连接起来, 来实现对石 墨烯和氧化石墨烯的功能化改性, 如图 26所示. 本文对 石墨烯点击功能化改性的反应过程和反应条件及其研 究方法作了详细的归类和系统的总结. 随着对石墨烯研 究的不断深入和新的合成方法的不断出现, 此表也有待 于进一步修正、完善和增补. 点击化学对石墨烯功能化 改性既灵活方便, 同时产率又比较高, 为石墨烯的研究 与应用提供了新的平台, 并使石墨烯能够更加广泛地应 用于纳米复合材料、光电材料、催化剂、化学传感器、 分子自组装以及药物传输等领域.

\section{5 石墨烯点击功能化改性的表征方法}

石墨烯点击功能化改性过程中涉及到的表征方法 较多, 笔者依据文献以及相关的仪器分析材料, 对一些 经常使用的检测方法及其检测目的做简要的总结和说 明，见表 3 . 
表 2 石墨烯和氧化石墨烯点击功能化改性

Table 2 The functionalization of Graphene and Graphene Oxide with "click" chemistry

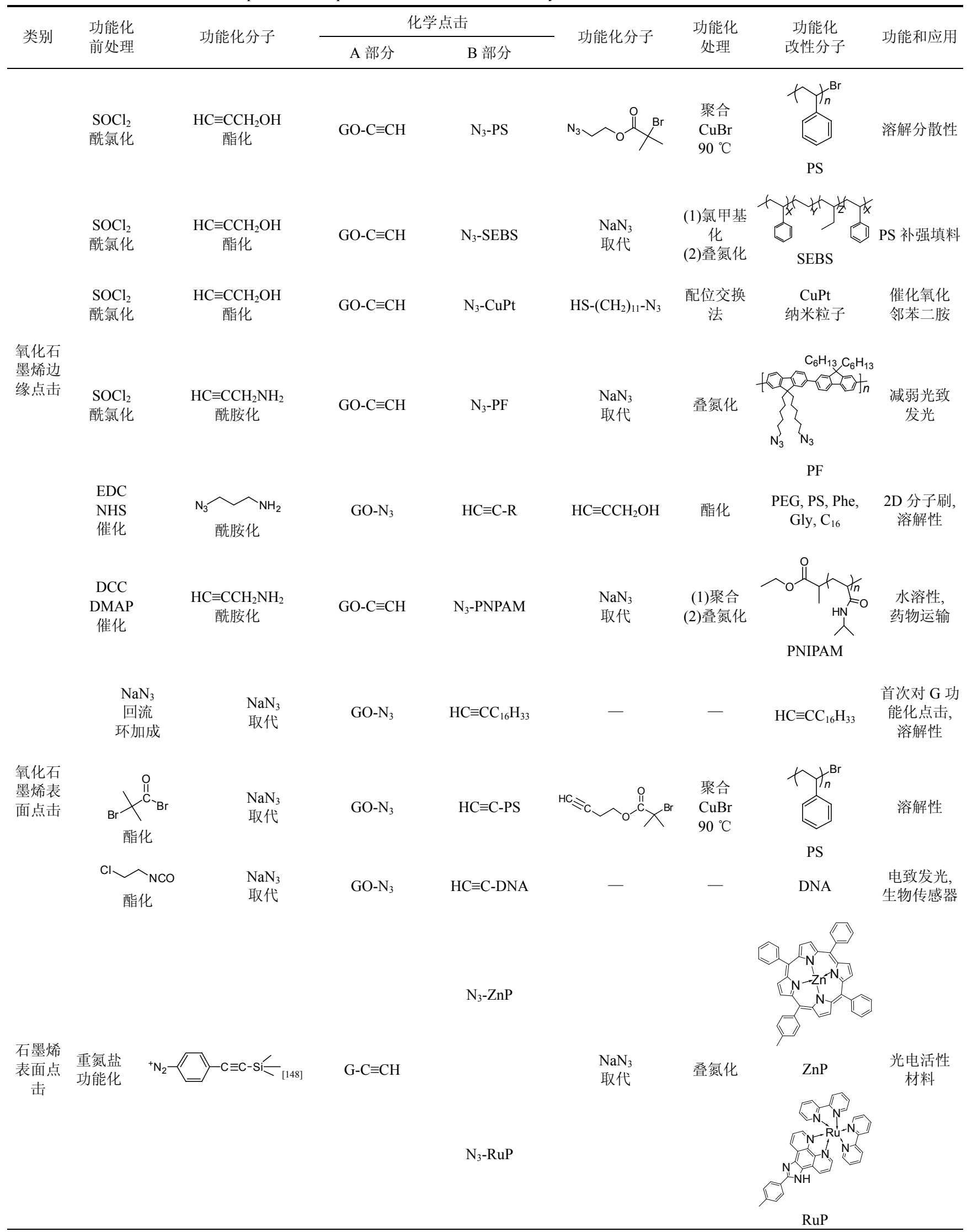


续表

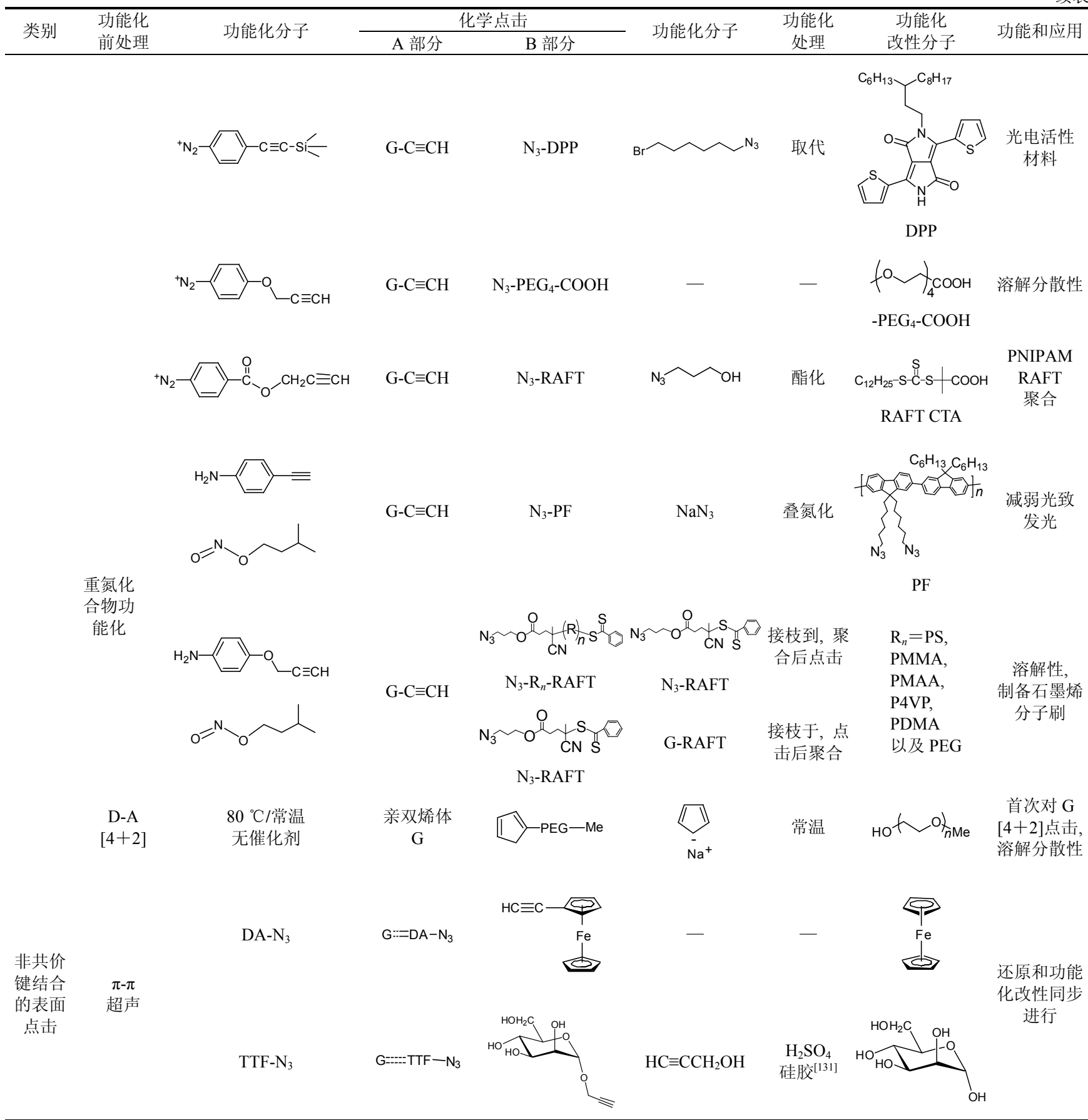

表中 “: : :=:” 指石墨烯与功能化分子之间以非共价键形式的 $\pi-\pi$ 堆积作用.

表 3 石墨烯点击功能化中常用的表征方法和结果

Table 3 The commonly characterization and results of the functionalization of graphene

\begin{tabular}{|c|c|c|c|c|}
\hline 表征内容 & 表征方法 & & 结果 & 结果说明 \\
\hline \multirow{5}{*}{$\begin{array}{l}\text { 分子 } \\
\text { 结构 }\end{array}$} & \multirow{5}{*}{ IR } & $\mathrm{C}=\mathrm{C}$ & 在 $1620 \mathrm{~cm}^{-1}$ 左右 & \multirow{3}{*}{$\begin{array}{l}\mathrm{GO} \text { 和 } \mathrm{RGO} \text { 中的部分常见特征峰; 一 } \\
\text { 般在 } 3450 \mathrm{~cm}^{-1} \text { 处出现较宽的峰, 归 } \\
\text { 结 } \mathrm{KBr} \text { 压片吸收了水分, 并且覆盖了 } \\
\text { 为 }-\mathrm{COOH} \text { 中 } \mathrm{O}-\mathrm{H} \text { 的伸缩振动; 有时 } \\
\text { 在 } 1630 \mathrm{~cm}^{-1} \text { 处出现水中的 } \mathrm{O}-\mathrm{H} \text { 弯 } \\
\text { 曲振动. }\end{array}$} \\
\hline & & $\mathrm{C}=\mathrm{O}$ & 在 $1725 \mathrm{~cm}^{-1}$ 左右 & \\
\hline & & 环氧 & 在 $1060 \mathrm{~cm}^{-1}$ 左右 & \\
\hline & & $-\mathrm{C} \equiv \underline{\mathrm{C}-\mathrm{H}}$ & 在 $3300 \mathrm{~cm}^{-1}$ 左右 & \multirow{2}{*}{$\begin{array}{l}\text { 炔基化的 } \mathrm{G}, \mathrm{GO} \text { 以及功能分子的特征 } \\
\text { 吸收峰, 点击反应后 } \mathrm{C} \equiv \mathrm{C} \text { 的特征吸收 } \\
\text { 峰的消失. }\end{array}$} \\
\hline & & $-\mathrm{C} \equiv \mathrm{C}-$ & 在 $2120 \mathrm{~cm}^{-1}$ 左右 & \\
\hline
\end{tabular}




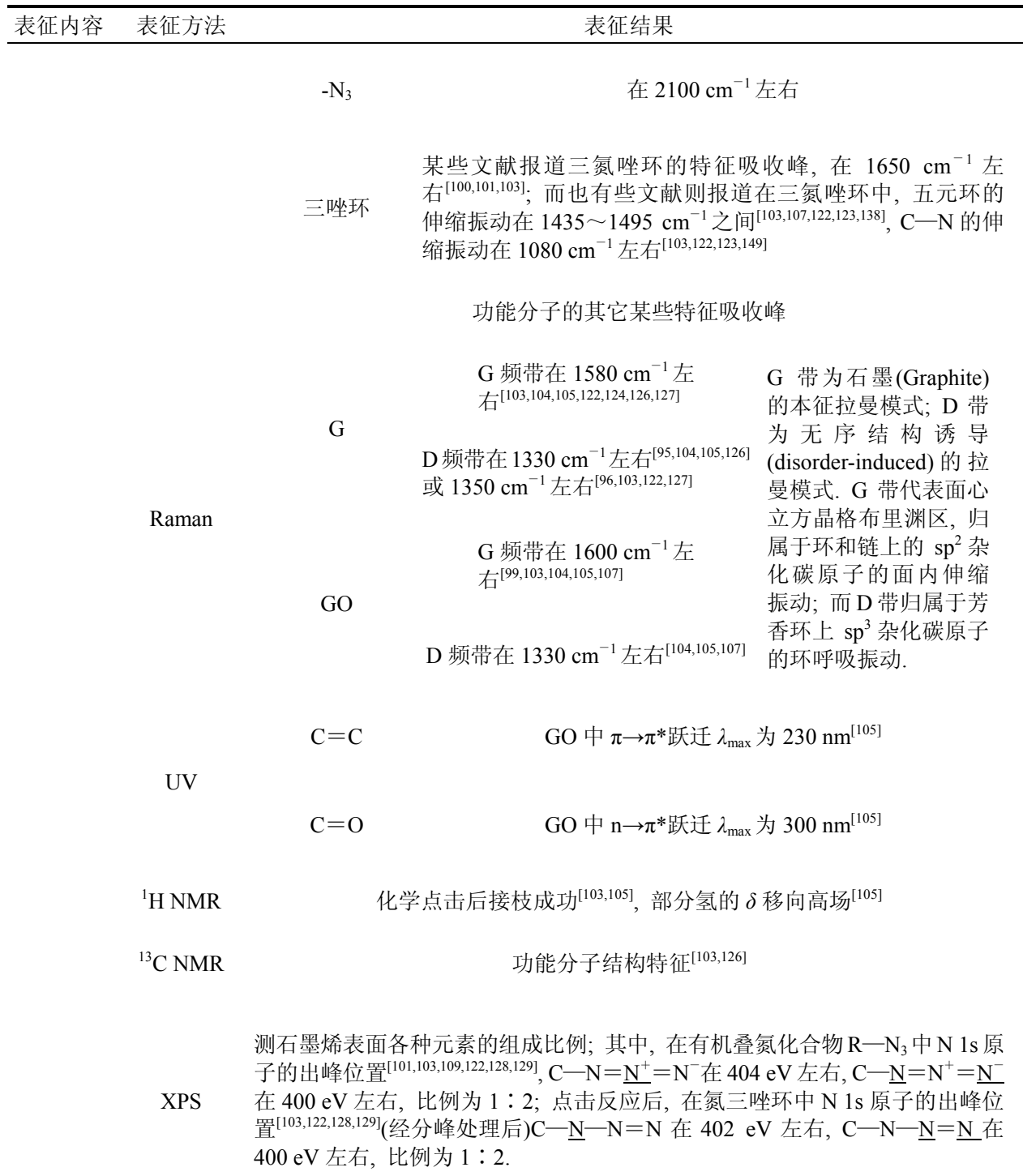

晶体 XRD 在 $9^{\circ} \sim 11.5^{\circ}$ 之间 ${ }^{[99,100,104,107,126,127]}$, 对应的 GO 的层间距 $d$ 为 结构 $0.97 \sim 0.74 \mathrm{~nm}$ (由于 $\mathrm{GO}$ 层吸收水份的量不同). 干燥 $\mathrm{GO}$ 的层 间距 $d$ 为 $0.59 \sim 0.67 \mathrm{~nm}$, 而水合 $\mathrm{GO}$ 的层间距约为 1.15 $\mathrm{nm}^{[150]}$

石墨烯以及功能化改性后的表面高度

观测石墨烯的微观结构 $101,104,106,107,109,122,125,126,127]$
叠氮化的特征吸收峰, 点击反应后 $-N_{3}$ 的特征吸收峰的消失.

点击反应后, 三氮唑环的特征吸收峰 可以直接证明点击反应成功.

功能分子本身结构的特性吸收峰

$I_{\mathrm{D}} / I_{\mathrm{G}}$ 比值增加, 表示 $\mathrm{G}$ 平面缺陷和孤 立双键的增加 ${ }^{[99]}$ (即 $\mathrm{sp}^{3}$ 杂化的碳原子 数目增加); $I_{\mathrm{D}} / I_{\mathrm{G}}$ 比值表示 $\mathrm{sp}^{3}$ 杂化 $\mathrm{C}$ 原子与 $\mathrm{sp}^{2}$ 杂化 $\mathrm{C}$ 原子的比例 ${ }^{[127]}$.

测试 $\mathrm{G}$ 或 $\mathrm{GO}$ 功能化后, 在复合物中 保留功能分子特征峰. 点击反应后, 共轭扩大, $\lambda_{\text {max }}$ 发生红移 ${ }^{[105,122]}$; 但也 有些功能化分子则是 $\lambda_{\text {max }}$ 蓝. 移 ${ }^{123]}$.

多用来表征 $\mathrm{G}$ 或 $\mathrm{GO}$ 上的功能化的小 分子.

测 $\mathrm{G}$ 或 $\mathrm{GO}$ 表面各种元素的组成比例; 在 $404 \mathrm{eV}$ 左右处的 $\mathrm{N} 1 \mathrm{~s}$ 原子的出峰 消失，而在氮三唑中 $\mathrm{C}-\mathrm{N}-\mathrm{N}=\mathrm{N}$ 在 $402 \mathrm{eV}$ 左右, $\mathrm{C}-\mathrm{N}-\mathrm{N}=\mathrm{N}$ 在 $400 \mathrm{eV}$ 左右, 比例为 $1: 2$, 直接证明氮三唑 存在, 说明点击反应成功 ${ }^{[70,72,91,98]}$.

计算 $\mathrm{G}$ 和 $\mathrm{GO}$ 片层之间的距离; $\mathrm{GO}$ 在 放置过程中因吸收水的量不同，层间 距也会稍有不同; GO 功能化后片层 之间距离将会进一步增大.

测试 G, GO 表面平整度; 计算 $\mathrm{G}, \mathrm{GO}$ 的层数以及功能化分子链与 $\mathrm{G}, \mathrm{GO}$ 之 间的连接情况; 当 $\mathrm{G}, \mathrm{GO}$ 表面出现单 个分子链相应的高度和宽度时, 可以 说明功能化分子链通过点击反应在 $\mathrm{G}, \mathrm{GO}$ 表面连接成功.

观察 $\mathrm{G}, \mathrm{GO}$ 的片层数, 功能化分子在 G, GO 上的连接情况, 以及其它微观 结构. 通过部分颗粒状(或者聚集态 比较明显的)功能化分子的结构, 可 以证明它们在 G, GO 上的连接情况, 说明点击反应成功.

观察 $\mathrm{G}$ 或 $\mathrm{GO}$ 的片层厚度, 以及功能 化后的表面形貌状况. 


\begin{tabular}{|c|c|c|c|}
\hline 表征内容 & 表征方法 & 表征结果 & 结果说明 \\
\hline $\begin{array}{l}\text { 电学 } \\
\text { 性能 }\end{array}$ & $\mathrm{CV}$ & 测试氧化还原电位 & $\begin{array}{l}\text { 测试 } \mathrm{G} 、 \mathrm{GO} \text { 、功能化分子以及 } \mathrm{G} \text { 、 } \\
\mathrm{GO} \text { 功能化复合材料在功能化前后改 } \\
\text { 性的氧化还原电位的变化, 用来描述 } \\
\text { 电化学性能的改变 }{ }^{997,103,123,128,129]} \text {. }\end{array}$ \\
\hline $\begin{array}{l}\text { 热稳 } \\
\text { 定性 }\end{array}$ & TGA & 热稳定性 & $\begin{array}{l}\text { 测试热稳定性, 并计算功能化分子在 } \\
\mathrm{G} \text { 或 } \mathrm{GO} \text { 上的质量百分比, 以及功能] } \\
\text { 分子链与 } \mathrm{C} \text { 原子数的比例 }{ }^{[104,105,127]} \text {, 平均多少个 } \mathrm{C} \text { 原子含一个功能化分 } \\
\text { 子链). }\end{array}$ \\
\hline $\begin{array}{l}\text { 溶解 } \\
\text { 分散 }\end{array}$ & 溶解分散性 & 溶解性、分散性 & 功能化效果 \\
\hline
\end{tabular}

由表 3 可知, 石墨烯和氧化石墨烯在点击功能化改 性过程中使用了 IR, Raman, UV, ${ }^{1} \mathrm{H}$ NMR, ${ }^{13} \mathrm{C}$ NMR, XPS, XRD, AFM, TEM, SEM, CV, TGA 等多种表征方 法. 其中, 能够直接证明点击化学成功表征方法是 IR 和 XPS. 在 IR 表征中, 点击反应后, $\mathrm{C} \equiv \mathrm{C}($ 一般在 2120 $\mathrm{cm}^{-1}$ 左右)和 $-\mathrm{N}_{3}$ (一般在 $2100 \mathrm{~cm}^{-1}$ 左右)的特征吸收峰 的消失, 可以证明点击反应成功; 某些文献报道三氮唑 环的特征吸收峰在 $1650 \mathrm{~cm}^{-1}$ 左右, 而也有些文献则报 道在三氮唑环中, 五元环的伸缩振动在 $1435 \sim 1495$ $\mathrm{cm}^{-1}$ 之间, $\mathrm{C}-\mathrm{N}$ 的伸缩振动在 $1080 \mathrm{~cm}^{-1}$ 左右, 则可以 直接证明点击反应成功. 另外在点击反应后, XPS 可以 测得在原来叠氮有机化合物中 $404 \mathrm{eV}$ 左右处的 $\mathrm{N} 1 \mathrm{~s}$ 原 子的出峰消失, 而在氮三唑中经分峰处理后, $\mathrm{C}-\mathrm{N}-\mathrm{N}$ $=\mathrm{N}$ 在 $402 \mathrm{eV}$ 左右, $\mathrm{C}-\mathrm{N}-\underline{\mathrm{N}}=\underline{\mathrm{N}}$ 在 $400 \mathrm{eV}$ 左右, 比例 为 $1: 2$, 这样可以直接证明氮三唑存在, 说明点击反应 成功. 本文的另外一项梳理工作就是对以上的表征方法 作简要的总结、分析和说明, 希望在对石墨烯点击功能 化改性的设计和合成操作过程中, 作出科学合理的检测 检验与表征说明.

\section{6 总结与展望}

石墨烯拥有许多独特优异的物理化学性能, 这使得 石墨烯在众多领域内具有极其广泛的应用, 这是近几年 科研领域里最热门的课题之一. 但是由于石墨烯在水和 有机溶剂中的溶解性不佳, 因此在一定程度上限制了石 墨烯的应用. 为解决这一难题, 石墨烯的功能化改性显 得尤为重要. 目前石墨烯的改性方法较多, 其中, 点击 化学具有简单高效和改性效果较好的特点, 因此在石墨 烯的功能化改性过程中占有独特而重要的地位. 同时, 点击化学在石墨烯的功能化改性领域的研究也是最近 一两年内的新热点. 本文就目前关于点击化学在石墨烯 和氧化石墨烯功能化改性方面的合成和应用做了详细 的总结, 将石墨烯和氧化石墨烯的点击功能化改性分为 两种情况: 即共价键结合的点击功能化改性和 $\pi-\pi$ 堆积 的非共价键作用的点击功能化改性. 其中, 由于石墨烯
和氧化石墨烯的空间二维平面结构的特性，因此共价键 结合又可细分为边缘点击功能化改性和表面点击功能 化改性. 本文在众多文献的基础上，对改性过程中的合 成方法和反应条件作了详细的归类和系统的总结. 一方 面, 在石墨烯和氧化石墨烯的点击功能化分类上包括: (1)氧化石墨烯边缘点击, 首先通过二氯亚砜和碳化二 亚胺类物质对氧化石墨烯边缘的羧基催化活化后，经酯 化或酰胺化反应再对氧化石墨烯进行边缘点击; (2)氧化 石墨烯表面点击, 氧化石墨烯与叠氮钠、酰溴衍生物、 异氧酸酯衍生物反应后, 经叠氮化再对氧化石墨烯进行 表面点击; (3)石墨烯表面点击, 通过重氮盐或重氮化合 物对石墨烯表面炔基化后，再对石墨烯进行表面点击; (4)通过 D-A [4+2]反应对石墨烯进行表面点击; (5)功能 化分子通过非共价键作用与石墨烯 $\pi-\pi$ 堆积之后再进行 点击反应. 另一方面, 通过点击反应在石墨烯和氧化石 墨烯功能化改性的纳米复合物的合成路线上，根据反应 的特点详细列出了对石墨烯或者氧化石墨烯进行炔基 化或者叠氮基化的连接方法和反应条件, 然后再对功能 化分子进行相应地叠氮基化或者炔基化的, 通过点击反 应将两部分连接起来, 完成石墨烯和氧化石墨烯功能化 改性. 同时还指出了石墨烯和氧化石墨烯功能化复合物 的功能特性和应用前景. 我们对这部分工作进行列表总 结, 然后通过作图列出功能化反应的具体分类和反应过 程. 在对石墨烯点击功能化改性的设计和操作过程中, 可以根据功能化分子的反应活性和溶解特性，选择适当 的炔基化或者叠氮化, 然后与相应的叠氮化或者炔基化 的石墨烯和氧化石墨烯通过点击反应进行功能化改性. 鉴于石墨烯点击功能化改性过程中涉及到的表征方法 较多, 本文的另一项梳理工作是列表总结了经常使用的 IR, Raman, UV, ${ }^{1} \mathrm{H}$ NMR, ${ }^{13} \mathrm{C}$ NMR, XPS, XRD, AFM, TEM, SEM, CV, TGA 等表征方法及性质检测, 指出了 常见的出峰位置以及表征结果和测试目的, 并作了简要 的总结、分析和说明.

点击化学在石墨烯功能化改性的合成和应用中, 既 简单灵活方便, 同时产率又比较高, 为石墨烯的研究与 


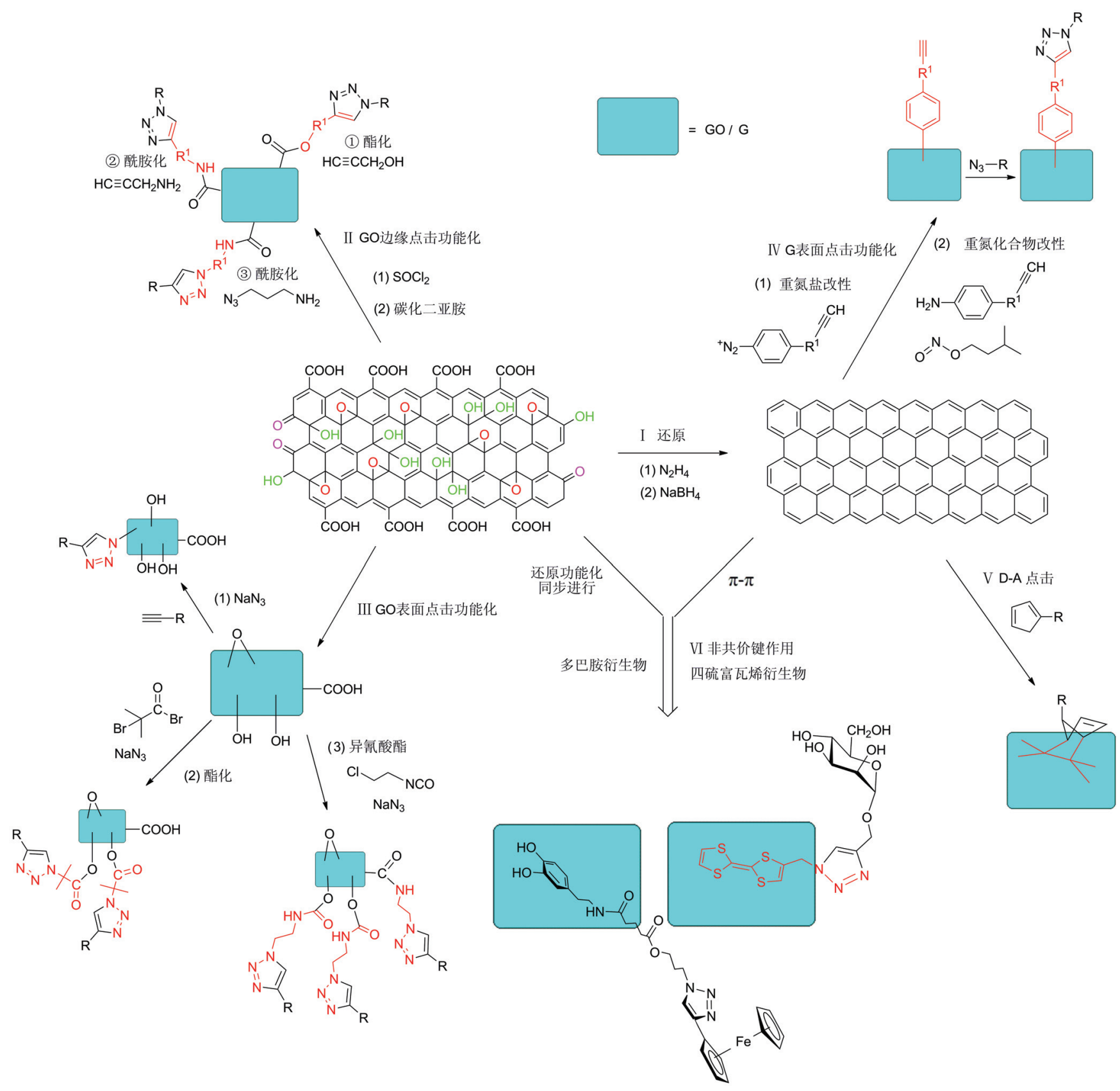

图 26 通过点击化学对 $\mathrm{G}$ 和 $\mathrm{GO}$ 进行点击功能化改性的各种方法的示意图

Figure 26 Schematic showing various functionalization of G and GO by click chemistry

应用提供了新的平台. 这将使其更加广泛地应用于纳米 复合材料、光电材料、催化剂、化学传感器、分子自组 装以及药物传输等领域. 点击化学在石墨烯纳米复合材 料合成方面的应用, 具有其它改性方法不可替代的优越 性. 一方面, 点击后形成了五元氮三唑的芳香环可以扩 大功能化分子与石墨烯之间的电子共轭离域范围, 这样 可以充分利用石墨烯的导电性以及载流子的传输性. 另 一方面，点击化学可以在石墨烯的边缘或表面上具有专 一的立体选择性, 既可以选择边缘连接方式, 也可以选 择表面连接方式, 这对于石墨烯材料特定区域的功能化 改性具有非常重大的意义.

尽管目前点击化学在石墨烯功能化改性中有着较
为广泛的应用, 但仍存在一些需要解决的问题和继续开 展的工作 ${ }^{[70]}$. (1)目前点击化学在石墨烯功能化改性中主 要的研究方向是 Huisgen 1,3-偶极环加成反应, 而其他 类型的点击反应并没有得到充分的应用与研究. 例如, (1) Diels-Alder 环加成反应; (2) 亲核开环反应, 特别是 张力杂环的亲电试剂开环; (3) 非醇醛的羰基化学; (4) 碳碳多键的加成反应. 因此, 其它新型点击反应的开发 与研究仍是该领域研究的主要方向之一. (2)通过点击化 学制备的石墨烯功能化改性纳米复合材料在生物传感 器、药物传输等领域的开发与应用, 使得金属催化剂 $\mathrm{Cu}(\mathrm{I})$ 本身所具有的毒性带来了许多潜在的负面影响. 因此, 无 $\mathrm{Cu}(\mathrm{I})$ 以及无金属催化的点击化学在石墨烯功 
能化改性中的应用将成为今后热门的研究方向. (3)石墨 烯通过点击化学后, 再与可逆加成一断裂链转移聚合法 (RAFT)和原子转移自由基聚合(ATRP)等活性自由基聚 合方法结合, 将为制备新型聚合物提供一种新的手段. (4)石墨烯纳米复合材料与点击化学作交叉学科涉及众 多领域, 而目前这方面的研究还比较少, 有许多方面还 有待于科学工作者进一步的研究和探索.

随着理论研究的逐步深入, 新的制备方法陆续出现 以及研究手段的不断发展完善, 必将使得石墨烯的研究 和应用变得更加深入和广泛。

\section{作者简介}

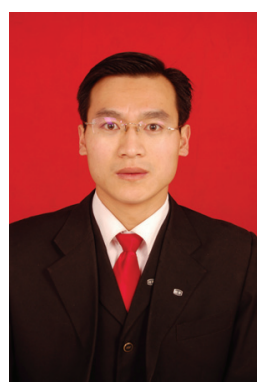

来常伟, 男, 东南大学材料物理与化学专业博士, 主要从 事光电材料和石, 墨烯复合材料的制备与研究.

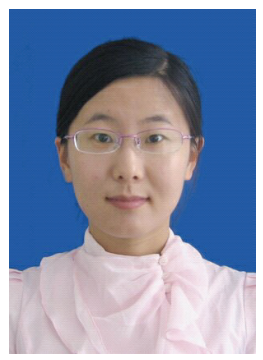

孙莹, 女, 东南大学化学化工学院讲师. 于 2007 年和 2012 年在东南大学化学化工学院分别取得学士和博士学位, 2009 年至美国华盛顿大学 Alex K-Y. Jen 课题组联合培养 2 年. 主要从事光电材料制备与性能研究. 已在 Chemistry of Materials, Journal of Materials Chemistry 等杂志发表 SCI 收录文章 十余篇.

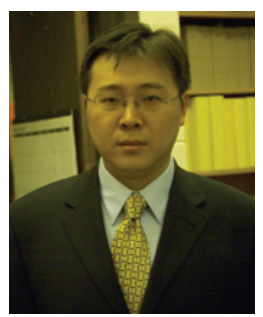

杨洪, 男, 副教授, 硕士生导师. 主要从事液晶材料、功 能高分子材料、高分子合成方法学、有机合成、杂环化学、 药物化学等研究方向. 在 Journal of the American Chemical Society, Journal of Material Chemistry, Soft Matter, Chemistry of Materials, Macromolecules 等国内外期刊发表论文 20 余篇; 论文被国内外同行引用 100 余次. 正在主持国家自然科学基
金青年基金、江苏省自然科学基金面上项目、人社部留学人 员择优资助计划重点项目、教育部留学回国人员科研启动基 金项目.

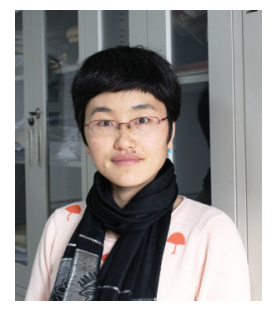

张雪勤, 女, 东南大学化学化工学院讲师, 主要从事功能 高分子材料, 聚合物凝聚态结构调控等方面的研究. 在 Journal of Polymer Science Part A: Polymer Chemistry, Polymer International 等杂志发表论文十余篇.

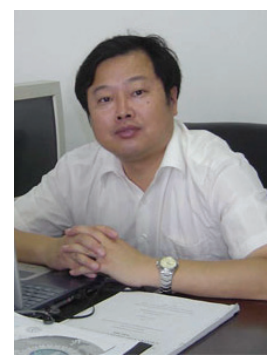

林保平, 男, 博士, 教授, 博士生导师, 现任东南大学化 学化工学院院长. 于 1982 和 1986 年毕业于南京工业大学化学 工程系, 分别获学士、硕士学位, 2005 年毕业于东南大学生物 医学工程专业, 获博士学位. 1989 年至今在东南大学化学化工 学院工作. 1990-1992、1998-1999 年留学日本国爱知工业大学, 从事高分子材料合成、表征等研究工作. 曾荣获 2011 年度江 苏省科学技术奖二等奖. 主要从事功能性聚氨酯的合成、表征 及应用, 低介电、高介电性聚酰亚胺功能材料的制备与性能研 究, 光敏银浆的制备及性能, 液晶材料的制备及应用, 光电转 换材料的制备及性能研究等方面的研究工作. 主持国家 “863” 高技术项目 “PDP 用无铅光敏电极浆料研究及工程化技术开 发”，主持和参与多项国家自然科学基金、江苏省自然科学基 金、江苏省成果转化基金、江苏省产学研前瞻性联合项目等 项目的研究. 已在国内外刊物及会议上发表学术论文 80 篇, 其中 SCI 收录 30 篇. 已申请国家发明专利 28 件, PCT2 件, 获 授权 15 件.

\section{References}

[1] Novoselov, K. S.; Geim, A. K.; Morozov, S. V.; Jiang, D.; Zhang, Y.; Dubonos, S. V.; Grigorieva, I. V.; Firsov, A. A. Science 2004, 306, 666.

[2] Geim, A. K.; Novoselov, K. S. Nat. Mater. 2007, 6, 183.

[3] Lee, C. G.; Wei, X. D.; Kysar, J. W.; Hone, J. Science 2008, 321, 385.

[4] Balandin, A. A.; Ghosh, S.; Bao, W.; Calizo, I.; Teweldebrhan, D.; Miao, F.; Lau, C. N. Nano Lett. 2008, 8, 902.

[5] Orlita, M.; Faugeras, C.; Plochocka, P.; Neugebauer, P.; Martinez, G.; Maude, D. K.; Barra, A. L.; Sprinkle, M.; Berger, C.; de Heer, W. A.; Potemski, M. Phys. Rev. Lett. 2008, 101, 267601.

[6] Novoselov, K. S.; Geim, A. K.; Morozov, S. V.; Jiang, D.; Katsnelson, M. I.; Grigorieva, I. V.; Dubonos, S. V.; Firsov, A. A. Nature 2005, 438, 197.

[7] Stoller, M. D.; Park, S. J.; Zhu, Y. W.; An, J. H.; Ruoff, R. S. Nano Lett. 2008, 8, 3498. 
[8] Reina, A.; Jia, X.; Ho, J.; Nezich, D.; Son, H.; Bulovic, V.; Dresselhaus, M. S.; Kong, J. Nano Lett. 2009, 9, 30.

[9] Nair, R. R.; Blake, P.; Grigorenko, A. N.; Novoselov, K. S.; Booth, T. J.; Stauber, T.; Peres, N. M. R.; Geim, A. K. Science 2008, 320, 1308.

[10] Kuilla, T.; Bhadra, S.; Yao, D.; Kim, N. H.; Bose, S.; Lee, J. H. Prog. Polym. Sci. 2010, 35, 1350.

[11] Stankovich, S.; Dikin, D. A.; Dommett, G. H. B.; Kohlhaas, K. M.; Zimney, E. J.; Stach, E. A.; Piner, R. D.; Nguyen, S. T.; Ruoff, R. S. Nature 2006, 442, 282.

[12] Sun, Y. Q.; Wu, Q.; Xu, Y. X.; Bai, H.; Li, C.; Shi, G. Q. J. Mater. Chem. 2011, 21, 7154.

[13] Zhang, L.; Li, C.; Liu, A. R.; Shi, G. Q. J. Mater. Chem. 2012, 22, 8438.

[14] Wu, Q.; Xu, Y. X.; Yao, Z. Y.; Liu, A. R.; Shi, G. Q. ACS Nano 2010, 4, 1963.

[15] Dai, J.; Lang, M.-D. Acta Chim. Sinica 2012, 70, 1237. (戴静，郎美 东, 化学学报, 2012, 70, 1237.)

[16] Chen, X.-Y.; Shi, Y.-L.; Yang, D.; Hu, J.-H.; Yang, P.-Y. Acta Chim. Sinica 2012, 70, 1. (陈小乙, 石远琳, 杨东, 胡建华, 杨芒原, 化 学学报, 2012, 70, 1.)

[17] Zhang, S.-P. Acta Chim. Sinica 2012, 70, 1394. (张树鹏, 化学学报, 2012, 70, 1394.)

[18] Zhang, Q.; Wu, S.-Y.; He, M.-W.; Zhang, L.; Liu, Y.; Li, J.-H.; Song, X.-M. Acta Chim. Sinica 2012, 70, 2213. (张谦, 吴抒遥, 何茂伟, 张玲, 刘洋, 李景虹, 宋溪明, 化学学报, 2012, 70, 2213.)

[19] Wang, H.-Z.; Gao, C.-X.; Zhang, P.; Yao, S.-W.; Zhang, W.-G. Acta Phys.-Chim. Sin. 2013, 29, 117. (王宏智, 高翠侠, 张鹏, 姚素薇, 张卫国, 物理化学学报, 2013, 29, 117.)

[20] Nogueira, A. F.; Longo, C.; Paoli, M. A. D. Coord. Chem. Rev. 2004, $248,1455$.

[21] Hou, Y.; Cheng, Y.; Hobson, T.; Liu, J. Nano Lett. 2010, 10, 2727.

[22] Heo, J.; Oh, J. W.; Ahn, H. I.; Lee, S. B.; Cho, S. E.; Kim, M. R.; Lee, J. K.; Kim, N. Synth. Met. 2010, 160, 2143.

[23] Li, Y.; Hu, Y.; Zhao, Y.; Shi, G. Q.; Deng, L. E.; Hou, Y. B.; Qu, L. T. Adv. Mater. 2011, 23, 776.

[24] Wang, J.-X.; Wang, K.-Z.; Yang, H.-Q.; Huang, Z. Acta Chim. Sinica 2011, 69, 2539. (王纪学, 王科志, 杨洪强, 黄吉, 化学学报, 2011, 69, 2539.)

[25] Xie, W.-J.; Fu, Y.-Y.; Ma, H.; Zhang, M.; Fan, L.-Z. Acta Chim. Sinica 2012, 70, 2169. (谢文菁, 傅英懿, 马红, 张沫, 范楼珍, 化 学学报, 2012,70, 2169.)

[26] Mohanty, N.; Berry, V. Nano Lett. 2008, 8, 4469.

[27] Lu, C. H.; Yang, H. H.; Zhu, C. L.; Chen, X.; Chen, G. N. Angew. Chem. Int. Ed. 2009, 48, 4785.

[28] Scheuermann, G. M.; Rumi, L.; Steurer, P.; Bannwarth, W.; Mulhaupt, R. J. Am. Chem. Soc. 2009, 131, 8262.

[29] Huang, C. C.; Bai, H.; Li, C.; Shi, G. Q. Chem. Commun. 2011, 47, 4962.

[30] Sun, Y. Q.; Li, C.; Xu, Y. X.; Bai, H.; Yao, Z.; Shi, G. Q. Chem. Commun. 2010, 46, 4740.

[31] Pernaut, J. M.; Reynolds, J. R. J. Phys. Chem. B 2000, 104, 4080.

[32] Liu, Z.; Robinson, J. T.; Sun, X.; Dai, H. J. Am. Chem. Soc. 2008, 130, 10876.

[33] Wintterlin, J.; Bocquet, M. L. Surf. Sci. 2009, 603, 1841.

[34] Kim, K. S.; Zhao, Y.; Jang, H.; Lee, S. Y.; Kim, J. M.; Kim, K. S.; Ahn, J. H.; Kim, P.; Choi, J. Y.; Hong, B. H. Nature 2009, 457, 706.

[35] Sutter, P. W.; Flege, J. I.; Sutter, E. A. Nat. Mater. 2008, 7, 406.

[36] Hernandez, Y.; Nicolosi, V.; Lotya, M.; Blighe, F. M.; Sun, Z. Y.; De, S.; McGovern, I. T.; Holland, B.; Byrne, M.; Gun'ko, Y. K.; Boland, J. J.; Niraj, P.; Duesberg, G.; Krishnamurthy, S.; Goodhue, R.; Hutchison, J.; Scardaci, V.; Ferrari, A. C.; Coleman, J. N. Nat. Nanotechnol. 2008, 3, 563.

[37] Stankovich, S.; Dikin, D. A.; Piner, R. D.; Kohlhaas, K. A.; Kleinhammes, A.; Jia, Y.; Wu, Y.; Nguyen, S.; Ruoff, R. S. Carbon 2007, $45,1558$.

[38] Park, S. J.; Ruoff, R. S. Nat. Nanotechnol. 2009, 4, 217.

[39] Inagaki, M.; Kim, Y. A.; Endo, M. J. Mater. Chem. 2011, 21, 3280.

[40] Pei, S.; Zhao, J.; Du, J.; Ren, W.; Cheng, H. M. Carbon 2010, 48, 4466.

[41] Xu, Y. X.; Sheng, K. X.; Li, C.; Shi, G. Q. J. Mater. Chem. 2011, 21, 7376.

[42] Hummers, W. S.; Offeman, R. E. J. Am. Chem. Soc. 1958, 80, 1339.

[43] Schniepp, H. C.; Li, J. L.; McAllister, M. J.; Sai, H.; Herrera-Alonso, M.; Adamson, D. H.; Prud'homme, R. K.; Car, R.; Saville, D. A.; Aksay, I. A. J. Phys. Chem. B 2006, 110, 8535.
[44] Szabó, T.; Berkesi, O.; Forgó, P.; Josepovits, K.; Sanakis, Y.; Petridis, D.; Dékány, I. Chem. Mater. 2006, 18, 2740.

[45] Mkhoyan, K. A.; Contryman, A. W.; Silcox, J.; Stewart, D. A.; Eda, G.; Mattevi, C.; Miller, S.; Chhowalla, M. Nano Lett. 2009, 9, 1058.

[46] Dreyer, D. R.; Park, S.; Bielawski, C. W.; Ruoff, R. S. Chem. Soc. Rev. 2010, 39, 228.

[47] Gao, W.; Alemany, L. B.; Ci, L. J.; Ajayan, P. M. Nat. Chem. 2009, 1, 403.

[48] Loh, K. P.; Bao, Q. L.; Ang, P. K.; Yang, J. X. J. Mater. Chem. 2010, $20,2277$.

[49] Salavagione, H. J.; Martínez, G.; Ellis, G. Macromol. Rapid Commun. 2011, 32, 1771 .

[50] Georgakilas, V.; Otyepka, M.; Bourlinos, A. B.; Chandra, V.; Kim, N.; Kemp, K. C.; Hobza, P.; Zboril, R.; Kim, K. S. Chem. Rev. 2012 $112,6156$.

[51] Bai, H.; Li, C.; Shi, G. Q. Adv. Mater. 2011, 23, 1089.

[52] Huang, C. C.; Li, C.; Shi, G. Q. Energy Environ. Sci. 2012, 5, 8848.

[53] Sun, Y. Q.; Shi, G. Q. J. Polym. Sci. Polym. B: Polym. Phys. 2013, $51,231$.

[54] Kuila, T.; Bose, S.; Mishra, A. K.; Kuila, T.; Bose, S.; Mishra, A. K.; Khanra, P.; Kim, N. H.; Leed, J. H. Prog. Mater. Sci. 2012, 57, 1061.

[55] Xu, Y. X.; Shi, G. Q. J. Mater. Chem. 2011, 21, 3311

[56] Sun, Y. Q.; Wu, Q.; Shi, G. Q. Energy Environ. Sci. 2011, 4, 1113.

[57] Li, Y.; Zhao, Y.; Cheng, H. H.; Hu, Y.; Shi, G. Q.; Dai, L. M.; Qu, L. T. J. Am. Chem. Soc. 2012, 134, 15.

[58] Xu, Y. X.; Wu, Q.; Sun, Y. Q.; Bai, H.; Shi, G. Q. ACS Nano 2010, 4, 7358.

[59] Zhao, Y.; Bai, H.; Hu, Y.; Li, Y.; Qu, L. T.; Zhang, S. W.; Shi, G. Q. J. Mater. Chem. 2011, 21, 13978.

[60] Sheng, K. X.; Bai, H.; Sun, Y. Q.; Li, C.; Shi, G. Q. Polymer 2011 $52,5567$.

[61] Bai, H.; Sheng, K. X.; Zhang, P. F.; Li, C.; Shi, G. Q. J. Mater Chem. 2011, 21, 18653.

[62] Xu, Y. X.; Sheng, K. X.; Li, C.; Shi, G. Q. ACS Nano 2010, 4, 4324.

[63] Sheng, K. X.; Xu, Y. X.; Li, C.; Shi, G. Q. New Carbon Mater. 2011, 26,9 .

[64] Zhang, X.; Yang, R.; Wang, C.; Heng, C.-L. Acta Phys.-Chim. Sin. 2012, 28, 1520 .

[65] Ma, W.-S.; Zhou, J.-W.; Lin, X.-D. Acta Chim. Sinica 2011, 69, 1463. (马文石, 周俊文, 林晓丹, 化学学报, 2011, 69, 1463.)

[66] Chen, X.; Braunschweig, A. B.; Wiester, M. J.; Yeganeh, S.; Ratner, M. A.; Mirkin, C. A. Angew. Chem. Int. Ed. 2009, 48, 5178.

[67] Li, H. M.; Cheng, F. O.; Duft, A. M.; Adronov, A. J. Am. Chem. Soc. 2005, 127, 14518.

[68] Zhang, W. B.; Tu, Y.; Ranjan, R.; Horn, R. M. V.; Leng, S.; Wang, J.; Polce, M. J.; Wesdemiotis, C.; Quirk, R. P.; Newkome, G. R.; Cheng, S. Z. D. Macromolecules 2008, 41, 515.

[69] Kolb, H. C.; Finn, M. G.; Sharpless, K. B. Angew. Chem. Int. Ed. 2001, 40, 2004

[70] Zhang, T.; Zheng, C.-H.; Cheng, X.; Ding, X.-B.; Peng, Y.-X. Prog. Chem. 2008, 20, 1090. (张涛, 郑朝晖, 成煦, 丁小斌, 彭宇行, 化 学进展, 2008, 20, 1090.)

[71] Lutz, J. F. Angew. Chem. Int. Ed. 2007, 46, 1018.

[72] Moses, J. E.; Moorhouse, A. D. Chem. Soc. Rev. 2007, 36, 1249.

[73] Liu, Q.; Zhang, Q.-Y.; Chen, S.-J.; Zhou, J.; Lei, X.-F. Chin. J. Org. Chem. 2012, 32, 1846. (刘清, 张秋禹, 陈少杰, 周健, 雷星锋, 有 机化学, 2012, 32, 1846.)

[74] Xiong, X.-Q.; Cai, L.; Tang, Z.-K. Chin. J. Org. Chem. 2012, 32, 1410. (熊兴泉, 蔡雷, 唐忠科, 有机化学, 2012, 32, 1410.)

[75] Devadoss, A.; Chidsey, C. E. D. J. Am. Chem. Soc. 2007, 129, 5370.

[76] Boisselier, E.; Salmon, L.; Ruiz, J.; Astruc, D. Chem. Commun. 2008, 44, 5788 .

[77] Kinge, S.; Gang, T.; Naber, W. J. M.; van der Wiel, W. G.; Reinhoudt, D. N. Langmuir 2011, 27, 570.

[78] Kiick, K. L.; Saxon, E.; Tirrell, D. A.; Bertozzi, C. R. Proc. Natl. Acad. Sci. U. S. A. 2002, 99, 19.

[79] Hong, V.; Presolski, S. I.; Ma, C.; Finn, M. G. Angew. Chem. Int. Ed. 2009, 48,9879 .

[80] Gierlich, J.; Burley, G. A.; Gramlich, P. M. E.; Hammond, D. M.; Carell, T. Org. Lett. 2006, 8, 3639.

[81] Such, G. K.; Quinn, J. F.; Quinn, A.; Tjipto, E.; Caruso, F. J. Am. Chem. Soc. 2006, 128, 9318.

[82] Lee, J. K.; Chi, Y. S.; Choi, I. S. Langmuir 2004, $20,3844$.

[83] Hahn, U.; Elhabiri, M.; Trabolsi, A.; Herschbach, H.; Leize, E.; Dorsselaer, A. V.; Albrecht-Gary, A. M.; Nierengarten, J. F. Angew. 
Chem. Int. Ed. 2005, 44, 5338 .

[84] Helms, B.; Mynar, J. L.; Hawker, C. J.; Fréchet, M. J. J. Am. Chem. Soc. 2004, 126, 15020.

[85] Englert, B. C.; Bakbak, S.; Bunz, U. H. F. Macromolecules 2005, 38, 5868.

[86] Khanttskyy, B.; Dallinger, D.; Kappe, C. O. J. Comb. Chem. 2004, 6,884 .

[87] Speers, A. E.; Adam, G. C.; Cravatt, B. F. J. Am. Chem. Soc. 2003, $125,4686$.

[88] Speers, A. E.; Cravatt, B. F. J. Am. Chem. Soc. 2005, 127, 10018.

[89] Hassane, F. S.; Frisch, B.; Schuber, F. Bioconjugate Chem. 2006, 17, 849.

[90] Kolb, H. C.; Sharpless, K. B. Drug Discovery Today 2003, 8, 1128.

[91] Huisgen, R. Proc. Chem. Soc. 1961, 357.

[92] Lutz, J. F.; Börner, H. G. Prog. Polym. Sci. 2008, 33, 1.

[93] Kotov, N. A.; Dékány, I.; Fendler, J. H. Adv. Mater. 1996, 8, 637.

[94] Stankovich, S.; Piner, R. D.; Chen, X.; Wu, N.; Nguyen, S. T.; Ruoff, R. S. J. Mater. Chem. 2006, 16, 155.

[95] Gomez-Navarro, C.; Weitz, R. T.; Bittner, A. M.; Scolari, M.; Mews, A.; Burghard, M.; Kern, K. Nano Lett. 2007, 7, 3499.

[96] Mattevi, C.; Eda, G.; Agnoli, S.; Miller, S.; Mkhoyan, K. A.; Celik, O.; Mastrogiovanni, D.; Granozzi, G.; Garfunkel, E.; Chhowalla, M. Adv. Funct. Mater. 2009, 19, 2577.

[97] Li, D.; Müller, M. B.; Gilje, S.; Kaner, R. B.; Wallace, G. G. Nat. Nanotechnol. 2008, 3, 101.

[98] Shin, H. J.; Kim, K. K.; Benayad, A.; Yoon, S. M.; Park, H. K.; Jung, I. S.; Jin, M. H.; Jeong, H. K.; Kim, J. M.; Choi, J. Y.; Lee, Y. H. Adv. Funct. Mater. 2009, 19, 1987.

[99] Sun, S. T.; Cao, Y. W.; Feng, J. C.; Wu, P. Y. J. Mater. Chem. 2010, 20,5605 .

[100] Cao, Y. W.; Lai, Z. L.; Feng, J. C.; Wu, P. Y. J. Mater. Chem. 2011, 21, 9271.

[101] Yang, H.; Kwon, Y.; Kwon, T.; Lee, H.; Kim, B. J. Small 2012, 8, 3161.

[102] Sommer, W. J.; Weck, M. Langmuir 2007, 23, 11991

[103] Castelaín, M.; Martínez, G.; Merino, P.; Martín-Gago, J. Á.; Segura, J. L.; Ellis, G.; Salavagione, H. J. Chem. Eur. J. 2012, 18, 4965.

[104] Kou, L.; He, H, K.; Gao, C. Nano-Micro Lett. 2010, 2, 177.

[105] Pan, Y. Z.; Bao, H. Q.; Sahoo, N. G.; Wu, T. F.; Li, L. Adv. Funct. Mater. 2011, 21, 2754.

[106] Salvio, R.; Krabbenborg, S.; Naber, W. J. M.; Velders, A. H.; Reinhoudt, D. N.; van der Wiel, W. G. Chem. Eur. J. 2009, 15, 8235.

[107] Yang, X. M.; Ma, L. J.; Wang, S.; Li, Y. W.; Tu, Y. F.; Zhu, X. L. Polymer 2011, 52, 3046.

[108] Laurent, B. A.; Grayson, S. M. J. Am. Chem. Soc. 2006, 128, 4238.

[109] Wang, Z. H.; Ge, Z. L.; Zheng, X. X.; Chen, N.; Peng, C.; Fan, C. H.; Huang, Q. Nanoscale 2012, 4, 394.

[110] Bahr, J. L.; Yang, J. P.; Kosynkin, D. V.; Bronikowski, M. J.; Smalley, R. E.; Tour, J. M. J. Am. Chem. Soc. 2001, 123, 6536.

[111] Bahr, J. L.; Tour, J. M. Chem. Mater. 2001, 13, 3823.

[112] Campidelli, S.; Ballesteros, B.; Filoramo, A.; Díaz Díaz, D.; Torre, G. D. L.; Torres, T.; Rahman, G. M. A.; Ehli, C.; Kiessling, D.; Werner, F.; Sgobba, V.; Guldi, D. M.; Cioffi, C.; Prato, M.; Bourgoin, J. P. J. Am. Chem. Soc. 2008, 130, 11503.

[113] Yadav, S. K.; Mahapatra, S. S.; Cho, J. W.; Lee, J. Y. J. Phys. Chem. C 2010, 114, 11395.

[114] Yadav, S. K.; Mahapatra, S. S.; Cho, J. W. Polymer 2012, 53, 2023.

[115] Sinitskii, A.; Dimiev, A.; Corley, D. A.; Fursina, A. A.; Kosynkin, D. V.; Tour, J. M. ACS Nano 2010, 4, 1949.

[116] Sharma, R.; Baik, J. H.; Perera, C. J.; Strano, M. S. Nano Lett. 2010, $10,398$.

[117] Bekyarova, E.; Itkis, M. E.; Ramesh, P.; Berger, C.; Sprinkle, M.; De Heer, W. A.; Haddon, R. C. J. Am. Chem. Soc. 2009, 131, 1336.

[118] Lomeda, J. R.; Doyle, C. D.; Kosynkin, D. V.; Hwang, W. F.; Tour, J.
M. J. Am. Chem. Soc. 2008, 130, 16201

[119] Koehler, F. M.; Jacobsen, A.; Ensslin, K.; Stampfer, C.; Stark, W. J. Small 2010, 6, 1125.

[120] Hossain, M. Z.; Walsh, M. A.; Hersam, M. C. J. Am. Chem. Soc. 2010, 132, 15399

[121] Adenier, A.; Combellas, C.; Kanoufi, F.; Pinson, J.; Podvorica, F. I. Chem. Mater. 2006, 18, 2021.

[122] Wang, H. X.; Zhou, K. G.; Xie, Y. L.; Zeng, J.; Chai, N. N.; Li, J.; Zhang, H. L. Chem. Commun. 2011, 47, 5747.

[123] Castelaín, M.; Salavagione, H.; Segura, J. L. Org. Lett. 2012, 14, 2798.

[124] Jin, Z.; McNicholas, T. P.; Shih, C. J.; Wang, Q. H.; Paulus, G. L. C.; Hilmer, A. J.; Shimizu, S.; Strano, M. S. Chem. Mater. 2011, 23 , 3362.

[125] Yang, Y. F.; Song, X. H.; Yuan, L.; Li, M.; Liu, J. C.; Ji, R. Q.; Zhao, H. Y. J. Polym. Sci. Part A: Polym. Chem. 2012, 50, 329.

[126] Ye, Y. S.; Chen, Y. N.; Wang, J. S.; Rick, J.; Huang, Y. J. H.; Chang, F. C.; Hwang, B. J. Chem. Mater. 2012, 24, 2987.

[127] Yuan, J. C.; Chen, G. H.; Weng, W. G.; Xu, Y. Z. J. Mater. Chem. 2012, 22, 7929 .

[128] Kaminska, I.; Das, M. R.; Coffinier, Y.; Niedziolka-Jonsson, J.; Sobczak, J.; Woisel, P.; Lyskawa, J.; Opallo, M.; Boukherroub, R.; Szunerits, S. Mater. Interfaces 2012, 4, 1016.

[129] Kaminska, I.; Barras, A.; Coffinier, Y.; Lisowski, W.; Roy, S.; Niedziolka-Jonsson, J.; Woisel, P.; Lyskawa, J.; Opallo, M.; Siriwardena, A.; Boukherroub, R.; Szunerits, S. ACS Appl. Mater. Interfaces 2012, 4, 5386.

[130] Canevet, D.; Salle, M.; Zhang, G. P.; Zhang, D.; Zhu, D. Chem. Commun. 2009, 45, 2245.

[131] Roy, B.; Mukhopadhyay, B. Tetrahedron Lett. 2007, 48, 3783.

[132] Kaminska, I.; Das, M. R.; Coffinier, Y.; Niedziolka-Jonsson, J.; Woisel, P.; Opallo, M.; Szunerits, S.; Boukherroub, R. Chem. Commun. 2012, 48, 1221.

[133] Lee, D. W.; Kim, T.; Lee, M. Chem. Commun. 2011, 47, 8259.

[134] Mann, J. A.; López, J. R.; Abruña, H. D.; Dichtel, W. R. J. Am. Chem. Soc. 2011, 133, 17614.

[135] Xu, Y. X.; Bai, H.; Lu, G. W.; Li, C.; Shi, G. Q. J. Am. Chem. Soc. 2008, 130, 5856.

[136] Dong, X. C.; Shi, Y. M.; Zhao, Y.; Chen, D. M.; Ye, J.; Yao, Y. G.; Gao, F.; Ni, Z. H.; Yu, T.; Shen, Z. X.; Huang, Y. X.; Li, L. J. Phys. Rev. Lett. 2009, 102, 135501.

[137] Wang, Q. H.; Hersam, M. C. Nat. Chem. 2009, 1, 206.

[138] Wang, Q. H.; Hersam, M. C. Nano Lett. 2011, 11, 589.

[139] Kozlov, S. M.; Viñes, F.; Görling, A. Carbon 2012, 50, 2482.

[140] Kozhemyakina, N. V.; Englert, J. M.; Yang. G.; Spiecker, E.; Schmidt, C. D.; Hauke, F.; Hirsch, A. Adv. Mater. 2010, 22, 5483.

[141] Xu, L. Q.; Wang, L.; Zhang, B.; Lim, C. H.; Chen, Y.; Neoh, K. G.; Kang, E. T.; Fu, G. D. Polymer 2011, 52, 2376

[142] Yuan, Y. L.; Gou, X. X.; Yuan, R.; Chai, Y. Q.; Zhuo, Y.; Ye, X. Y.; Gan, X. X. Biosens. Bioelectron. 2011, 30, 123.

[143] Gan, X. X.; Yuan, R.; Chai, Y. Q.; Yuan, Y. L.; Cao, Y. L.; Liao, Y. H.; Liu, H. J. Anal. Chim. Acta 2012, 726, 67.

[144] Niu, X. L.; Yang, W.; Guo, H.; Ren, J.; Gao, J. Z. Biosens. Bioelectron. 2013, 41, 225

[145] Hu, Y. W.; Li, F. H.; Bai, X. X.; Li, D.; Hua, S. C.; Wang, K. K.; Niu, L. Chem. Commun. 2011, 47, 1743.

[146] Hu, Y. W.; Wang, K. K.; Zhang, Q. X.; Li, F. H.; Wu, T. S.; Niu, L. Biomaterials 2012, 33, 1097.

[147] Xu, Y. X.; Zhao, L.; Bai, H.; Hong, W. J.; Li, C.; Shi, G. Q. J. Am. Chem. Soc. 2009, 131, 13490.

[148] Lowe, A. B.; McCormick, C. L. Prog. Polym. Sci. 2007, 32, 283.

[149] Ryu, B. Y.; Emrick, T. Angew. Chem. Int. Ed. 2010, 49, 9644.

[150] Lerf, A.; Buchsteiner, A.; Pieper, J.; Schöttl, S.; Dekany, I.; Szabo, T.; Boehm, H. P. J. Phys. Chem. Solids 2006, 67, 1106. 